THE UNIVERSITY OF MANITOBA

\title{
EFFECTS OF A MENTAI TRAINING PACKAGE ON AN ENDURANCE PERFORMANCE
}

\author{
by \\ Thomas D. Patrick
}

\begin{abstract}
Submitted to
The Faculty of Graduate studies

In Partial Fulfillment

of the Requirements for the Degree
\end{abstract}

Master of Science

Faculty of Physical Education \& Recreation

Studies

University of Manitoba

Winnipeg, Manitoba

(c) 1995 
Acquisitions and

Bibliographic Services Branch

395 Wellington Street

Ottawa, Ontario

K1A ON4
Direction des acquisitions et

des services bibliographiques

395 , rue Wellington

Ottawa (Ontario)
Your file Voire référence

Our fite Notre réfrence
The author has granted an irrevocable non-exclusive licence allowing the National Library of Canada to reproduce, loan, distribute or sell copies of his/her thesis by any means and in any form or format, making this thesis available to interested persons.
L'auteur a accordé une licence irrévocable et non exclusive permettant à la Bibliothèque nationale du Canada de reproduire, prêter, distribuer ou vendre des copies de sa thèse de quelque manière et sous quelque forme que ce soit pour mettre des exemplaires de cette thèse à la disposition des personnes intéressées.

L'auteur conserve la propriété du droit d'auteur qui protège sa thèse. Ni la thèse ni des extraits substantiels de celle-ci ne doivent être imprimés ou autrement reproduits sans son autorisation. 
ON AN ENDURANCE PERFORMANCE

BY

THOMAS D. PATRICK

A Thesis submitted to the Faculty of Graduate Studies of the University of Manitoba in partial fulfillment of the requirements of the degree of

MASTER OF SCIENCE

(C) 1995

Permission has been granted to the LIBRARY OF THE UNIVERSITY OF MANITOBA to lend or sell copies of this thesis, to the NATIONAL LIBRARY OF CANADA to microfilm this thesis and to lend or sell copies of the film, and LIBRARY MICROFILMS to publish an abstract of this thesis.

The author reserves other publication rights, and neither the thesis nor extensive extracts from it may be printed or other-wise reproduced without the author's written permission. 


\section{Abstract}

The purpose of this study was to examine the effects of a mental training package on the performance of a 1600 metre run. Subjects were 3 male tri-athletes and 1 male elite runner. A single-subject multiple-baseline-acrossindividuals design was employed to evaluate the treatment package. The results demonstrated that the mental training package was clearly effective in improving the running performance of the three subjects receiving the intervention. The social validation results were favorable and indicated that the subjects enjoyed using the mental training package and were pleased with the results obtained. Further, the coaches surveyed felt that the results were important, especially those attained with the elite athlete. 
Table of contents

Abstract ii

Table of Contents ii

Ch. 1 INTRODUCTION 1

Purpose of the study 2

Delimitations 4

Limitations $\quad 4$

Definition of Terms 5

$\begin{array}{lll}\text { Ch. } 2 \text { REVIEW OF LITERATURE } & 7\end{array}$

$\begin{array}{ll}\text { Imagery } & 7\end{array}$

Relaxation $\quad 9$

$\begin{array}{ll}\text { Self-talk } & 10\end{array}$

Goal-setting $\quad 12$

Mental Training Packages 13

Mental Training and Running Performance 15

Single-subject Design $\quad 16$

$\begin{array}{lll}\text { Ch. } 3 & \text { METHODS AND PROCEDURES } & 19\end{array}$

$\begin{array}{ll}\text { Sample } & 19\end{array}$

Experimental Design 20

Instrumentation $\quad 20$

Intervention Procedures $\quad 21$

Procedural Reliability Assessment $\quad 22$

Treatment of the Data 23 
Ch. 4 RESULTS

Reliability Evaluations

Procedural Reliability Evaluations

Ch. 5

DISCUSSION

Mental Skills Assessment

Mental Training Workbook

Social Validation Questionnaire 


\section{List of Tables}

Table 1: Mean Results Data

List of Figures

Figure 1: $\quad$ Subjects' Time to Complete $1600 \mathrm{~m}$ Run 28

Figure 2: $\quad$ Subject One's Running Times 30

Figure 3: $\quad$ Subject One's Mental Skills Usage 31

Figure 4: $\quad$ Subject Two's Running Times 32

Figure 5: Subject Two's Mental Skills Usage 33

Figure 6: $\quad$ Subject Three's Running Times 35

Figure 7: $\quad$ Subject Three's Mental Skills Usage 36

Figure 8: $\quad$ Subject Four's Running Times $\quad 37$

Figure 9: $\quad$ Subject Four's Mental Skills Usage 38 


\section{Chapter 1}

Introduction

There has been very little consensus within the literature in defining the term "mental training". Iso-Ahola (1992) defines mental training as "individual training that strives systematically and purposefully to improve an athlete's cognitive and affective skills needed in sport performance" (p. 216). For an athlete to be successful within the current sport environment, especially at the elite level, they must be able to attain a "peak performance". Jackson and Roberts (1992) refer to peak performance as a state of superior functioning that characterizes optimal sport performance, resulting in outstanding personal achievements. In order to perform at this optimal level it is generally believed that the athlete must be in control of their emotions and cognitions (and correspondingly, their behavior).

Numerous studies have shown mental skills training to be an effective intervention in enhancing performance (e.g. Kirschenbaum \& Bale, 1984; Kendall, Hrycaiko, Martin, \& Kendall, 1990). In a review of studies testing the effectiveness of various psychological interventions, Greenspan and Feltz (1989) concluded that, educational relaxation-based interventions and remedial cognitive restructuring interventions are effective in improving the performance of collegiate and adult athletes in competitive 
situations. However, other researchers have noted that more controlled studies are required before more definitive conclusions can be made (Weinberg \& Williams, 1993).

Rushall (1989) has suggested that most Olympic finalists are similar in physiological capacity and skill efficiency. Their potential for success, as indicated by being medal contenders, is determined by psychological factors. Overall, there is ample evidence that supports the use of mental skills training to enhance an athlete's performance. There exists, however, very little within the literature to demonstrate that a mental skills training package will enhance an athletic endurance performance. Burhans, Richman, \& Bergey (1988) were able to demonstrate that superior running speeds were attained by those subjects that utilized mental imagery before running. Likewise, Bull (1989) found some support for the use of visualization, self-talk, and relaxation strategies to enhance the performance of an ultra-distance runner. Clearly, further research must be conducted in this area to examine the benefits of a mental skills training package for endurance athletes.

The purpose of this study was threefold. First, it was the goal of this study to examine the effectiveness of a cognitive-behavioral mental training package combining imagery rehearsal, relaxation, self-talk, and goal-setting to enhance a 1600 metre running performance. 
wollman (1986) stated that single-subject methodology may be preferential when working with athletes who will not improve much from pre-training levels; "small consistent changes may be seen in a single-subject design but not emerge significantly in a group design" (p. 136). Bryan (1987) also supports this view and notes that utilizing single-subject design eliminates the problem of group averages and any lack of statistical significance obscuring improvements in individual performance. It was, therefore, the second goal of this study to utilize single-subject design, not only as an appropriate methodological tool with which to study the effects of the mental training package, but to further expand the use of this experimental design within the sport psychology literature.

Finally, the third goal of this study was to determine whether the treatment package utilized was socially valid. Social validation attempts to assess the subject and significant others' evaluations of: a) the goals of the treatment program, b) the procedures that were used (the intervention), and, c) the significance of the results obtained (Martin \& Pear, 1992).

In summary, this study examined the effects of a cognitive-behavioral mental training package, consisting of imagery rehearsal, relaxation, self-talk, and goal-setting, on an endurance performance (specifically, to determine if an improvement can be demonstrated for athletes running a 
distance of 1600 metres). Finally, the intervention and procedures used were assessed for social validity.

\section{Delimitations}

1. The study was limited to one male elite runner and three male triathletes.

2. Due to the nature of the dependent variable (a "best effort" 1600 metre run) two data points were collected, on average, per week which permitted physiological recovery and ensured that no interference took place with the athletes' regular training schedules.

3. The behavior measured in the study was limited to the time (in seconds) to complete the 1600 metre run.

\section{Limitations}

1. The subject's ability to learn mental skills within a one week period may have affected the initial strength of the intervention effect.

2. The experimenter's ability to monitor the subject's use of the mental skills was limited to questionnaire data provided by the subjects. 
Definition of Terms

\section{Mental Training}

Mental training is individual training that strives systematically and purposefully to improve an athlete's cognitive and affective skills.

\section{Imagery}

Imagery involves internal representations (images) and/or feelings of the performance of a behavior, without the full physical movements associated with that behavior having been performed. Imagery can also involve images and feelings of the situation within which the behavior occurs.

\section{Self-talk}

Self-talk consists of overt or covert self-statements that affect an individual's behavior by acting as signals that a particular response will be reinforced.

\section{Relaxation}

Relaxation is the ability of an individual to release physical tension and achieve a state of mental calmness through various techniques including: deep centering breathing, self-statements, and visualization. 
Goal

A goal is a standard or level of performance towards which an individual or group direct their efforts in order to obtain a reinforcer.

\section{Goal-setting}

Goal-setting involves using "goals" to influence an individual (or group)'s behavior to work towards some objective (usually attainment of a reinforcer or reinforcing situation) over a period of time. 


\author{
Chapter 2 \\ Review of Literature
}

\begin{abstract}
There exists within the literature several different approaches for utilizing a mental skills package as an intervention to improve an athletic performance. of importance when selecting an appropriate mental training program is to ensure that the program is the most effective intervention possible (Kazdin 1992). Vealy (1988) conducted a content analysis of psychological skills training approaches within published books in North America between 1980 and 1988. The results of this analysis demonstrated that of the various psychological skills training methods presented within the published books, the four most commonly found included: imagery (100\%), physical relaxation (93\%), thought control (93\%), and goal-setting (70\%). A brief review of each of these skills follows, predominantly focusing on the most current, sport relevant articles that support the use of each skill as a component in a mental training package.
\end{abstract}

Imagery

Research suggests that imagery can play a crucial role in facilitating an optimal performance (Orlick \& Partington, 1988). Most mental training programs are built around the skill of mental imagery (Rodgers, Hall, \& Buckolz, 1991). 
Feltz and Landers (1983) conducted a meta-analysis of the effects of mental practice on motor skill learning and performance. They concluded that across many types of motor tasks, those who mentally practiced performed significantly better than the control groups.

Li-Wei, Qi-Wei, Orlick, and Zitzelsberger (1992) conducted a field study to assess the effects of mental imagery on children's' accuracy and technical quality of their forehand shots in ping pong. The results indicated that children who used mental imagery experienced significantly greater improvement in the accuracy and technical quality of their shots.

Mahoney, Gabriel and Perkins (1987) identified psychological skills that would differentiate elite and nonelite athletes. They determined that relative to their nonelite peers, the elite athletes in their study reported that they relied more on internally focused and kinesthetic imagery than on third-person visual forms of mental preparation. This finding with respect to the importance of having internal imagery as opposed to an external perspective is further supported by Mahoney \& Avener (1977) and Rotella, Gansneder, Ojala and Billing (1980).

In a study by Salmon, Hall, \& Haslam (1994), the use of imagery by soccer players of various skill levels was investigated. They concluded that the elite athletes reported employing more imagery than non-elite athletes regardless of the function imagery served. 
Although ample support has been demonstrated in support of the use of imagery, wollman (1986) stated, in response to the meta-analysis provided by Feltz \& Landers (1983), that: "Certainly the results are too inconsistent to reasonably guarantee experimental success in any given motor performance situation. Nor can it be assured that imagery, the mental practice technique of concern here, was the causal factor in any particular real-life anecdotal sport's success" (p. 135). Andre \& Means (1986) stated that although there is a substantial amount of research in this area (mental imagery) much of it is anecdotal or methodologically weak.

An important consideration in predicting the effectiveness of imagery is the quality of the imaging itself. Orlick (1986) suggests that well-developed imagery consists predominantly of: not only "seeing" but "feeling" the image, using imagery every day in many situations, and imaging in the actual speed of the skill or behavior to be performed.

Relaxation

Athletes need a certain amount of arousal or motivation to accomplish a task. However, too much activation can be detrimental to the athletes performance not only due to the physical tensing of muscles, thereby, restricting movement, but also because the feelings associated with nervousness 
can act as cues for negative thoughts which can be an impairment to the athlete's performance (Orlick, 1986; Harris and Williams, 1993). Once trained in relaxation, athletes can use this skill to lower general muscular tension under any condition.

In support of using relaxation as a component within a mental training package, Suinn, (1977) and weinberg, Seaborne, \& Jackson, (1981) indicated that using imagery alone is not as effective as when imagery is used in combination with relaxation.

In a study by Wrisberg and Anshel (1989), mental imagery combined with arousal adjustment was shown to have been a useful pre-shot cognitive strategy that young athletes used to enhance their free throw shooting performance. Finally, Straub (1989), Kirschenbaum \& Bale (1984), and Kenitzer \& Briddell (1991) put forth strong support for the use of relaxation techniques as an appropriate strategy within their mental skills training programs.

Self-talk

Cognitive behavior modification strategies have been utilized by sport psychologists to improve and optimize athletic performance (Silva, 1982). Verbalization, the attachment of useful or meaningful verbal descriptions to situations or movements to be remembered or learned, is a 
useful strategy for the improvement of performance (Rodgers, et al, 1991).

In a study by Rushall, Hall, Roux, Sasseville, and Rushall (1988), significant effects in performance enhancement were attained when negative self-talk was replaced with more appropriate task-oriented self-talk. Ziegler (1987) examined the effects of a four step verbal cueing program on the acquisition of forehand and backhand returns by beginning tennis players. Each group showed an acceleration in skill acquisition during the intervention phase of the study. Further support has been provided by Okwumabua, Meyers, Schleser, \& Cooke (1983), Rushall (1984), and Bunker, Williams, \& Zinsser (1993).

There is ample support in the research literature to demonstrate that self-talk is an important component for performance enhancement. Some important considerations with respect to the content of the self-talk in endurance events (an activity that involves repetitive movements) include the following. At least two thirds of the thought patterns and statements should involve self-statements about technique (Rushall, 1979). Secondly, performances should be segmented (Orlick, 1986), that is, the performances should be broken down into different situations such as: the first kilometer of the race, the first hill, etc. Thirdly, the athletes should be encouraged to use natural cues to prompt particular thoughts (Martin \& Lumsden, 1987). Finally, as an athlete begins to experience fatigue, the use of anti- 
fatigue thoughts that either focus on technique (as mentioned by Rushall) or alternatively, specific coping self-statements that will deal with the fatigue would prove most beneficial (Martin \& Lumsden, 1987).

Goal-setting

Locke and Latham (1985) suggested that goal-setting can increase the skill and confidence of athletes in competitive sports. Gould (1993) stated that goal-setting has been shown to influence the performance of athletes of varied age and ability levels and has also been linked to positive changes in confidence, anxiety levels, and motivation. He further suggested that goal setting is clearly a technique that sport psychologists should regularly employ. Goals appear to be most effective, as specified by Gill (1986), when they are specific, immediate, challenging but attainable, and stated in behavioral terms so that progress can be measured.

Hall, Weinberg, \& Jackson (1987) reported that subjects who identified specific goals performed a greater number of contractions on a hand dynamometer endurance task than a "do your best" group. Similarly, goal-setting and modelinggoal-setting groups performed a jumping task significantly better than a control group (Erbaugh and Barnett, 1986). Wolko, Hrycaiko, and Martin (1993) investigated the effects of two types of self-regulation strategies, one 
involving public components, the other private. Three of the five subjects showed enhanced performance using the private self regulation treatment package which included private self-goal-setting. More importantly, four of the five subjects attained their goals most often in the prementioned condition.

Using Mental Skills in a Mental Training Package

Landers (1992) has referred to mental training methods as cognitive-behavioral interventions which consist of: imagery, relaxation, biofeedback, hypnotherapy, cognitive restructuring, systematic desensitization, self-monitoring, performance-contingent rewards, and goal-setting. Rushall (1989) stated that cognitive-behavioral factors are the most important determinants of performance enhancement at the highest levels of competition. Further, in a review by Greenspan \& Feltz (1989), strong support for a relationship between cognitive-behavioral interventions and the enhancement of a sport performance was concluded.

From the reviews reported, the most frequently used skills in mental training programs in sport are imagery, self-talk, relaxation strategies and self-monitoring (goalsetting). Many studies have investigated certain combinations of mental skills to assess their effects on the enhancement of performance. Hall and Rodgers (1989) 
indicated that mental training programs often involve multiple techniques used in conjunction with one another.

Furthermore, Azrin (1977) stated that using a package is desirable in order to produce the greatest probability of treatment success. The focus should be on the result that can be achieved when applying an intervention to a client/subject. Determining which psychological skill was most responsible for the enhancement of performance is of interest, but "little seems to be gained by limiting oneself to partial benefits initially in order to achieve conceptual purity" (Azrin, p. 144). The research literature contains a number of studies utilizing treatment packages involving mental skills training to enhance performance.

Kendall et al, (1990) developed a mental training program involving imagery rehearsal, relaxation and selftalk to investigate the effects on basketball game performance. Using a multiple-baseline-across-subjects single-subject research design, they demonstrated a clear improvement in performance with all four female intercollegiate basketball players.

The effects of a comprehensive psychological skills training program for collegiate tennis players was explored by Daw and Burton (1994). The players were exposed to three psychological skills (goal-setting, imagery, and arousal regulation) and then given the opportunity to develop individualized programs. The results, utilizing case studies, provided strong support for the effectiveness of 
individual psychological skills training programs for tennis players. Further support for using a combination of mental skills in a training program were reported by Hamilton and Fremouw (1985) who assessed the effects of a cognitivebehavioral package on basketball free-throw performance.

Effects of Mental Training on a Running Performance

Bull (1989) conducted a case study investigating the effects of visualization, self-talk, and relaxation on the performance of an ultra-distance runner. Favorable results were reported but due to the nature of the study (a single case study), further research is necessary to provide additional support for the effectiveness of this intervention strategy.

Okwumabua, et al. (1983) conducted an investigation comparing cognitive strategies on the performance of new runners. Those runners who employed relatively more dissociate cognitive strategies demonstrated a greater reduction in running time over initial trials. However, the novice runners reported increasingly associative cognitive strategies as they gained running experience and physical proficiency.

Weinberg, Smith, Jackson, and Gould (1984), reported that no effects for cognitive strategies could be found when the subjects performed a thirty minute run, whereas the subjects who performed a muscular leg-endurance task showed 
better performance in the dissociation and positive selftalk conditions. Contrary findings by Silva and Appelbaum (1989) suggested that the top finishers at the olympic trials utilized both associative and dissociative techniques while the low finishers demonstrated a predominately dissociative tendency. These studies are inconclusive with respect to the efficacy of using cognitive techniques to improve running performance.

Martin and Pear (1992) pointed out that improved intervention effects are demonstrated when the behavioral components of a cognitive behavior modification treatment package are employed. This fact may account for the lack of support for cognitive interventions' effect on a running performance. This conclusion also provides further support for the use of behavioral components in the package as opposed to a cognitive intervention alone. Although some support does exist, further research is required in order to determine whether a cognitive-behavioral mental training package can enhance endurance performance.

Using Single-Subject Designs in Applied Research

Zaichkowsky (1980) suggested the importance of the use of single-subject design methodology when conducting research in sport psychology. Zaichkowsky (1980) made reference to two important considerations. First, having a no-treatment group is usually considered unacceptable by 
both coaches and athletes. Second, averaging of results to compare between groups ignores the effect of the intervention on the individual which, although not statistically significant, can be of practical significance for the athlete.

Martin and Hrycaiko (1983) further promoted the use of single-subject designs in sport psychology by demonstrating its relevance when assessing effective behavioral coaching. By utilizing frequent measurement of an individual's behavior, one can better assess progress and determine the effectiveness of an intervention. An additional important aspect in support of using single-subject design is the ability of the individual to serve as their own control thus eliminating the need for obtaining a large number of similar individuals required when utilizing group design (Martin \& Hrycaiko, 1983).

Wollman (1986) argued that single-subject design was an appropriate methodology when determining the effectiveness of imagery rehearsal on an athlete's performance. Wollman also advocated the use of single-subject design when evaluating psychological interventions for enhancing sport performance.

Bryan (1987) provided further support of utilizing single-subject designs when conducting research to determine the effects of an intervention on real-life athletic performance at both practices and during competitions. Similar to Martin \& Hrycaiko (1983), Bryan (1987) observed 
that obtaining a control group may be impossible, especially when working with an "elite" population. Finally, singlesubject design has been demonstrated as an effective research methodology in numerous studies, including: Kendall, et al., 1990; Hazen, Johnstone, Martin \& Srikameswaran, 1990; Mckenzie \& Liskevych, 1983; Hume, Martin, Gonzalez, Cracklen, \& Genthon, 1985.

In conclusion, it has been suggested that mental training can facilitate peak performance if training strategies are followed in a systematic manner. Numerous studies have showed positive effects when employing a mental skills training program with athletes to enhance their performance. However, very few of these studies have investigated whether similar results can be generalized to athletes performing endurance events. 


\section{Chapter 3 \\ Methods and Procedures}

Sample

The sample consisted of one male elite national level runner and three male triathletes ranging in age from twenty-five to thirty-seven years. The runner specialized in the 1500 metre distance and was a member of a local running club. The triathletes were all members of a local triathlon club. All of the subjects in the study had limited exposure to mental skills training. Although all of the subjects had some exposure to physical relaxation strategies (i.e. stretching to feel loose) and displayed some attempts at goal-setting, none utilized mental skills training in a systematic manner within their pre-training preparation.

Originally, the sample consisted of two male national level runners but one had to drop out immediately prior to the beginning of the study due to injury. As a result, the replacement subject (the third triathlete) was not available until the second session and could not participate in the final session due to a previous commitment. It was felt that the advantage of beginning the study with four qualified subjects offset the impact of the loss of two data points. 
Experimental Design

A single-subject design referred to as a multiple baseline across subjects (Martin \& Pear, 1992) was utilized for this study. This design required that a pre-treatment assessment (baseline phase) of the dependent variable (time to complete a distance of $1600 \mathrm{~m})$ be obtained. The intervention (imagery, relaxation, self-talk, and goalsetting) was introduced once the dependent variable was either stable (relatively consistent over time) or demonstrated a trend in the opposite direction of the anticipated change with the introduction of the treatment for each subject (Kazdin, 1992).

A sequential introduction of the intervention was continued until all of the subjects (except the control subject, who was kept in baseline phase through almost the entire study), received the experimental treatment. Due to a lack of presence of a visible training effect, the control subject was presented with the intervention before the final two training sessions.

Instrumentation

The dependent variable (time to complete the 1600 metre run) was measured by two observers concurrently in order to ensure that the dependent measures were reliable (i.e. inter-observer reliability, Martin \& Pear, 1992). To obtain 
consistency in scoring, both observers kept track of lap counts and subsequent lap/split times using a check sheet (appendix A) to ensure that the distance was completed on each trial. Before the start of the session, one observer was delegated as the primary observer, and their data was utilized unless the primary observer indicated that their time was not accurate (i.e. did not start the timer promptly upon the start of the 1600 metre run, or did not stop the timer accurately upon the completion of the run).

In addition to the behavioral data, a questionnaire was administered at the completion of each run to determine to what extent the mental skills were utilized by the subject after each trial (appendix B). These results were used as a manipulation check to ensure that the subjects were using the mental skills introduced to them during the intervention. The questionnaire data also provided information as to what degree the subjects were using each specific psychological skill within the treatment package.

Intervention Procedures

The intervention was administered to each subject individually over a period of two sessions. Each session was conducted off site between time trials and covered two mental skills each for a total of two sessions. The experimenter worked through each exercise once within the workbook with the subject to assist in the learning process. 
A third session was utilized to answer any questions the athlete had before completion of the intervention component. The subjects also watched a video entitled "What you see is what you get" which introduced the skill of visualization (imagery rehearsal) (Botterill, 1987).

Following the presentation of the intervention, each subject was contacted daily to ensure that they were completing the assignments in the workbook. Furthermore, the experimenter made himself available for any questions the subjects had when completing their homework assignments.

\section{Procedural Reliability Assessment}

To ensure that the subjects received the same information, each subject was given a standardized workbook and homework assignments to better familiarize themselves with the related skills (appendix C). Further, the workbook contained exercises and report sheets that would standardize the mental practice to ensure that they occurred as intended (Wollman, 1986).

Each session was delivered similarly to each subject by utilizing a standardized behavioral checklist(appendix D) that the experimenter, along with an observer completed as each component was discussed with the subject. This procedure ensured that the treatment was applied in a consistent manner. 
Treatment of the Data

The raw scores obtained were plotted according to the time (in seconds) it took the subject to complete the 1600 metre run on each session. Subsequently, the scores of the mental skills questionnaire were plotted throughout the sessions in order to assess the effects of the intervention on the subject's usage and understanding of the mental skills.

Evaluation of Results

\section{Scientific Assessment of Treatment Effects}

The data collected was graphed and then inspected visually to determine whether a significant effect had occurred. According to Martin and Pear (1992), one has greater confidence that a significant experimental effect had been observed: the greater number of times the effect is replicated across subjects; the fewer the number of overlapping data points between the pre-treatment and treatment phases; the more immediate the effect is observed following the introduction of the treatment; the larger the effect in comparison to baseline; and the more consistent the findings are within the related literature. 


\section{Clinical (Practical) Assessment of Treatment Effects}

Wolf (1978) stated that a social validity assessment involves asking three questions: 1) to what extent are the target behaviors identified for the treatment the most important to the client (subject) and/or society (or significant others such as coaches, parents, or peers); 2) are the particular procedures used deemed acceptable to the subject (client), and; 3 ) are the consumers of the treatment program satisfied with the results obtained?

At the end of the study, each participant completed a social validation questionnaire (appendix E) to provide information pertaining to the study's relative importance to the subjects, and ascertain the validity of the intervention itself. Further, several coaches were selected to complete a questionnaire that solicited their professional opinions of the experiment and of the results obtained (appendix $F$ ). only those coaches who participated with either provincial of national level athletes were surveyed in order to ascertain a specific established level of expertise. 


\section{Chapter 4}

\section{Results}

Reliability Evaluations

Correlations for the two recorders' scores were as follows: .9996 for subject 1's scores; .9996 for subject 2 's scores; .9936 for subject 3's scores; and .9961 for subject $4^{\prime} \mathrm{s}$ scores.

Except for subject 3 , in session 3, and subject 2 in session 11, all of the times utilized in the study were obtained from the primary observer's recorded times. In session 3, the primary observer did not start the timer promptly, therefore, the secondary observer's time was used in this instance. In session 11, the primary observer did not accurately stop the timer upon subject 2 's completion of the final lap, therefore, the secondary observer's time was utilized.

Procedural Reliability Evaluations

All of the subjects completed all of the exercises within the mental skills workbook. Subsequently, every session within the intervention phase included the completion of every imagery assessment questionnaire (p. 7, appendix $C$ ) and of every training evaluation form (p. 15, appendix C) . 
The observer verified that all aspects of the behavioral checklist (appendix D) were delivered to each subject within the intervention. Of importance, to facilitate the subject's self-talk, an oval drawing representing the 400 metre track was made for each subject to map out their run and indicate what thoughts or selfstatements would be made at specific points throughout their next run. This was an element in addition to the workbook found in appendix $\mathrm{C}$ and was completed with each subject during the examination of each subjects' self-talk.

Intervention Effects

The effect of the intervention on each subject's time to complete the 1600 metre run is shown graphically in Figure 1; while a numerical comparison of baseline and intervention average time for the 1600 metre run is presented in Table 1 . In the three subjects, the average time to complete the run decreased during the intervention phase, with subject 1 displaying the largest difference in time between phases.

Subject 1 received the intervention first after the third session and displayed an immediate effect (see Figure 2). On average, subject 1 demonstrated a 28.95 second decrease in time to run the 1600 metre distance throughout the intervention phase as compared to the baseline condition. Further, subject I's usage of mental skills went 
from a 25 - 38 percent rate during the baseline phase, to 100 percent throughout the entire intervention phase (see Figure 3).

Subject 2 received the intervention after the fifth session. Although there was an immediate effect, the first 1600 meter time after introduction of the intervention was not lower than previous times displayed during the baseline condition (see Figure 4). Session seven, however, did yield a time lower than any run for subject 2 to that point in the study and this new level of performance was maintained throughout the rest of the intervention phase.

On average, subject 2 demonstrated a 10.85 second decrease in time to run the 1600 metre distance throughout the intervention phase as compared to the baseline condition (see Table 1). Further, subject 2's usage of mental skills went from a 55.25 percent average during the baseline phase, to a 92.5 percent average throughout the intervention phase. Of importance, the last 3 sessions consisted of a 100 percent usage of mental skills which corresponds to subject 2's three best 1600 metre running times (see Figure 5). Subject 2 reported some difficulty obtaining images before the run on the first two sessions after introduction of the intervention. Not surprisingly, therefore, lower mental skills usage scores for subject 2's first two intervention sessions were reported. 
Subject 1

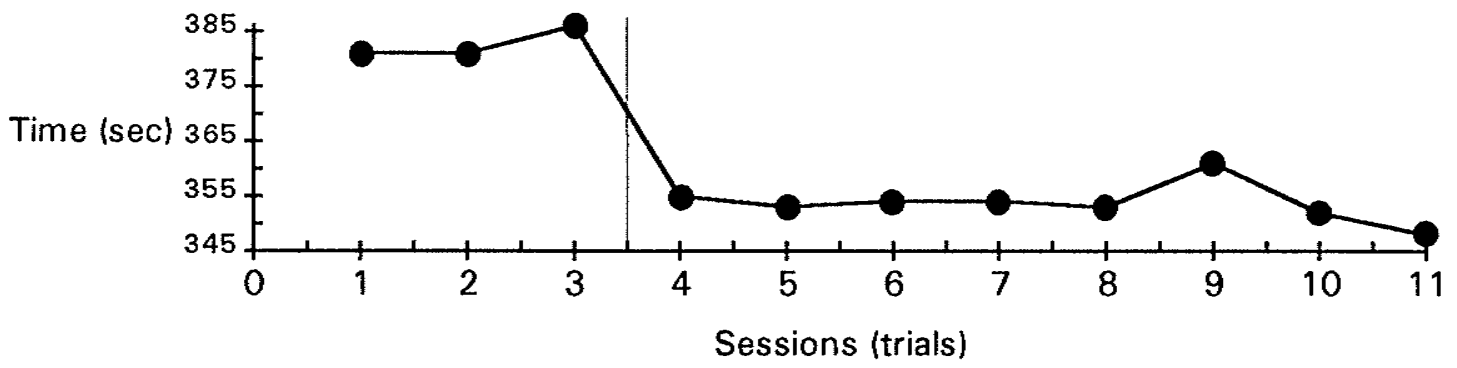

Subject 2

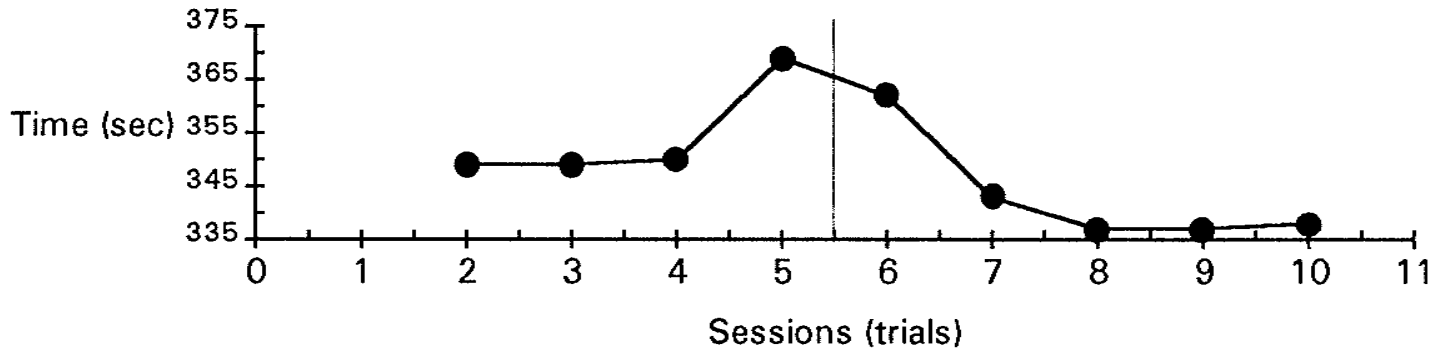

Subject 3

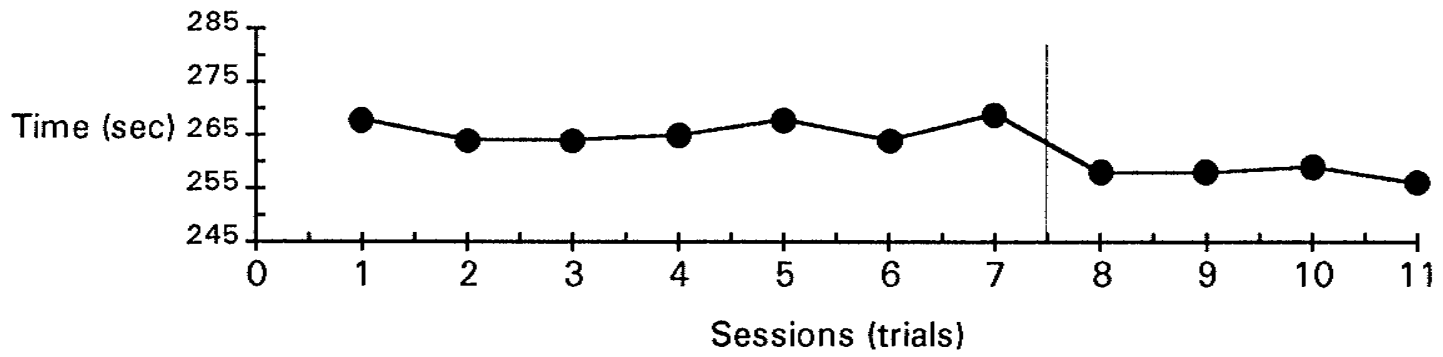

Subject 4-Control

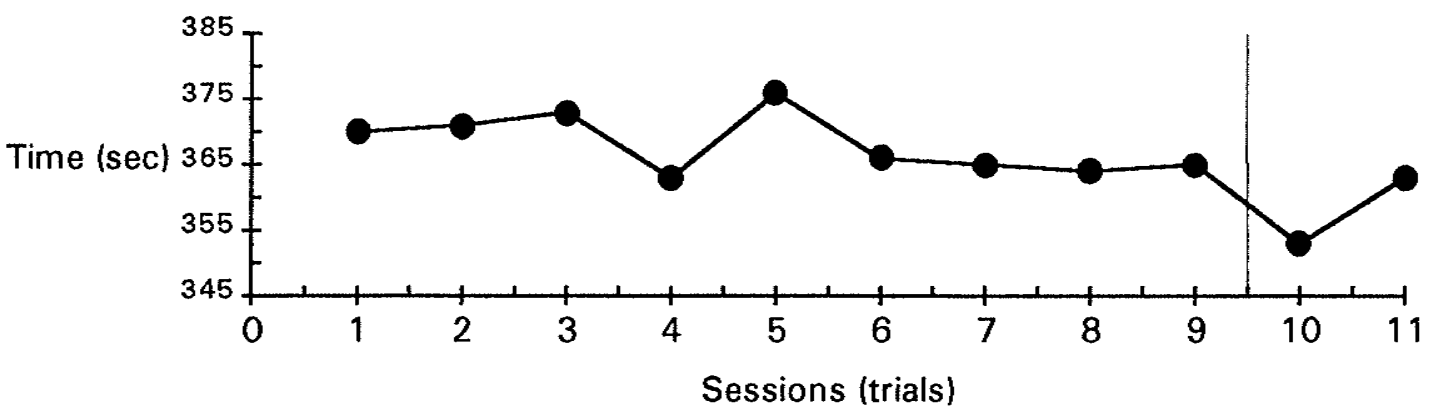

Figure 1. Subjects' time to complete the 1600 metre run. 
Table 1

Subjects' Average Number of Seconds to Complete 1600 Metre Run Comparing Baseline and Intervention Conditions

\begin{tabular}{|c|c|c|c|}
\hline Subject \# & $\begin{array}{c}\text { Average Time } \\
\text { During Baseline } \\
\text { Phase }\end{array}$ & $\begin{array}{c}\text { Average Time } \\
\text { During } \\
\text { Intervention } \\
\text { Phase }\end{array}$ & $\begin{array}{c}\text { Average } \\
\text { Decrease in } \\
\text { Subject's Time }\end{array}$ \\
\hline 1 & $382.70 \mathrm{sec}$ & $353.75 \mathrm{sec}$ & $-28.95 \mathrm{sec}$ \\
\hline 2 & $354.25 \mathrm{sec}$ & $343.40 \mathrm{sec}$ & $-10.85 \mathrm{sec}$ \\
\hline 3 & $266.00 \mathrm{sec}$ & $257.75 \mathrm{sec}$ & $-8.25 \mathrm{sec}$ \\
\hline 4 & $368.11 \mathrm{sec}$ & N/A & N/A \\
\hline
\end{tabular}


Subject 1

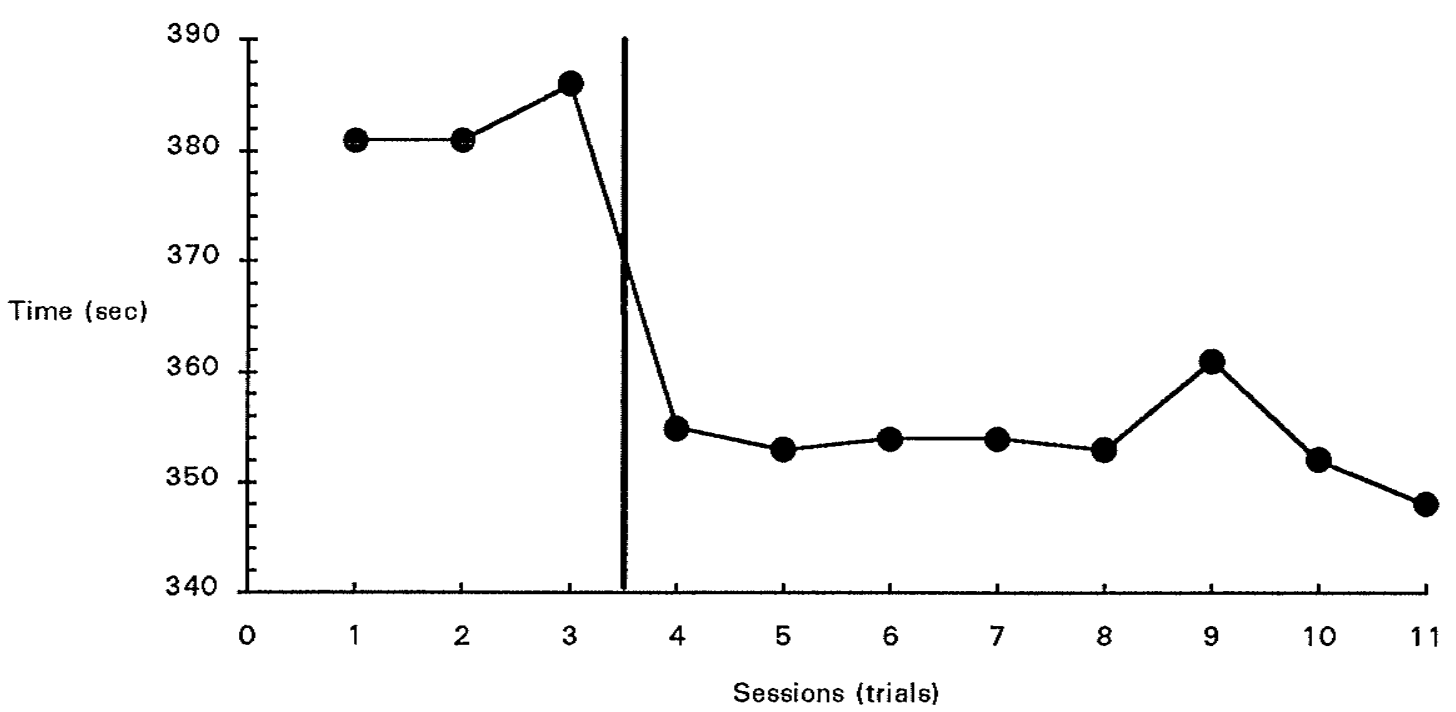

Figure 2. A graphical display of Subject 1's 1600 metre running time. 


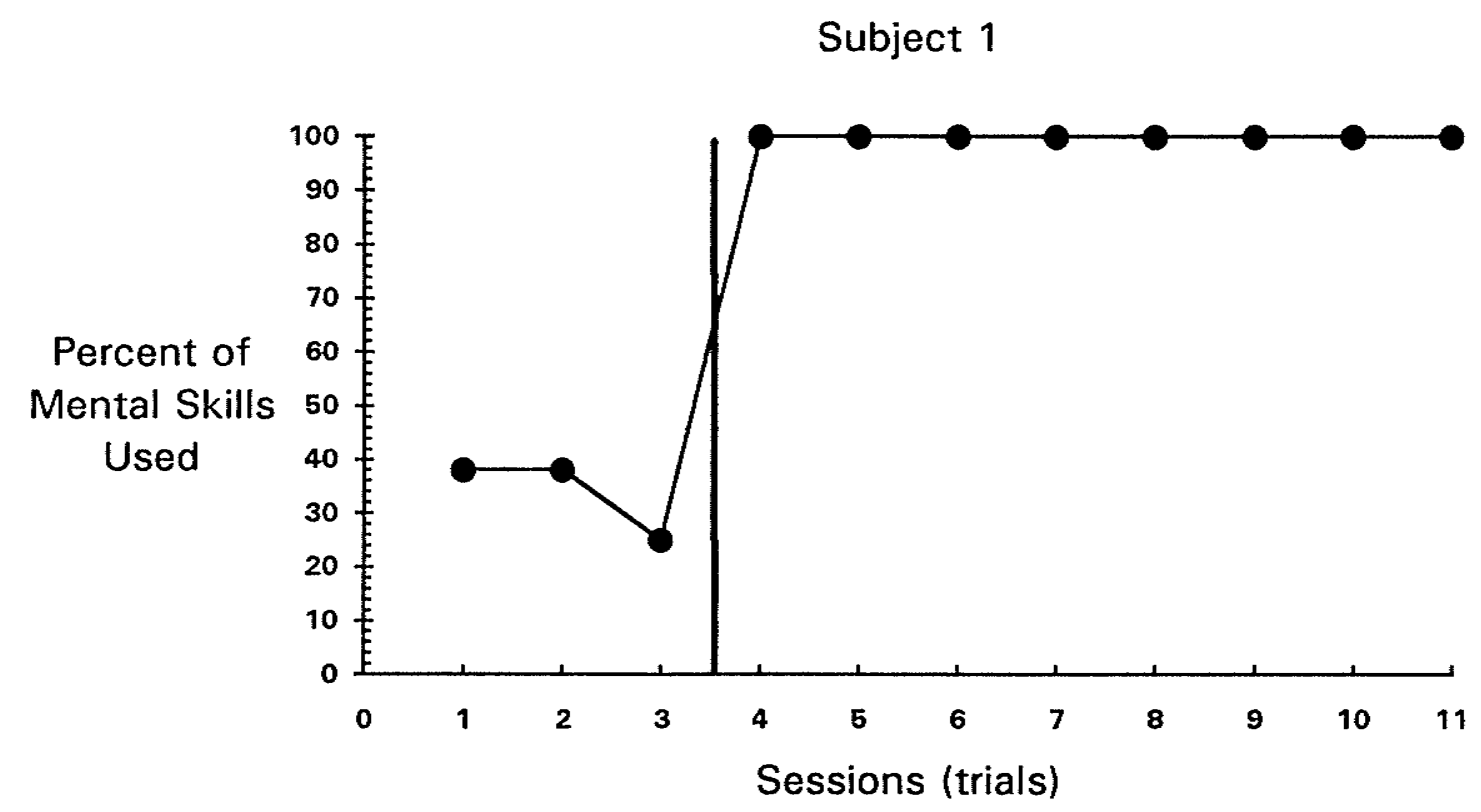

Figure 3. A graphical display of the percentage of mental skills utilized before and during the 1600 metre run. 
Subject 2

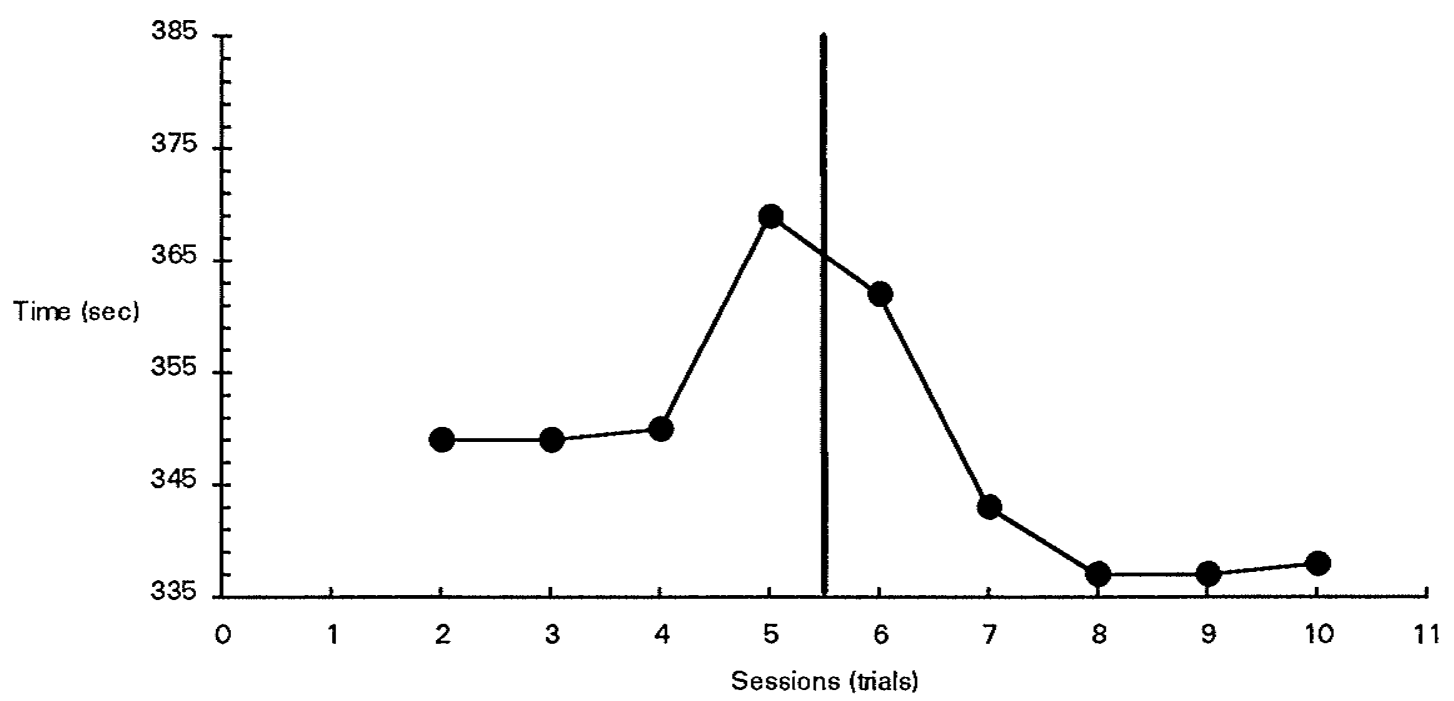

Figure 4. A graphical display of subject 2's 1600 metre running time. 
Subject 2

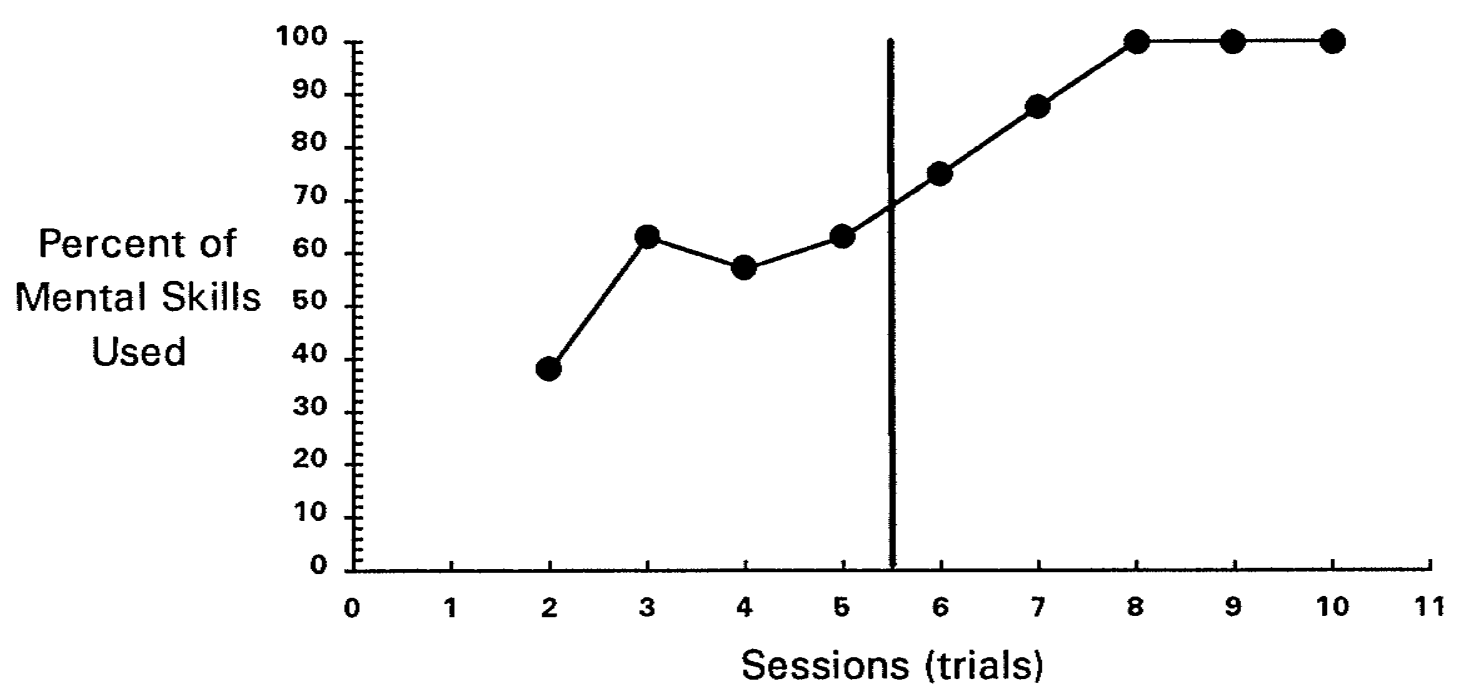

Figure 5. A graphical display of the percentage of mental skills utilized before and during the 1600 metre run. 
Subject 3 received the intervention after the seventh session and displayed an immediate effect (see Figure 6). On average, subject 3 demonstrated an 8.25 second decrease in time to run the 1600 metre distance throughout the intervention phase as compared to the baseline condition (see Table 1).

Subject 3's usage of mental skills went from a 28.86 percent average during the baseline phase to a 100 percent level throughout the entire intervention phase (see Figure 7) .

After the ninth session, the data was inspected to determine whether any training effect could be observed in subject 4. From the graphical data, it was determined that no clear training effect was present and it was therefore decided to deliver the intervention to the final subject, although the two data points following intervention were not sufficient to assess a trend. 


\section{Subject 3}

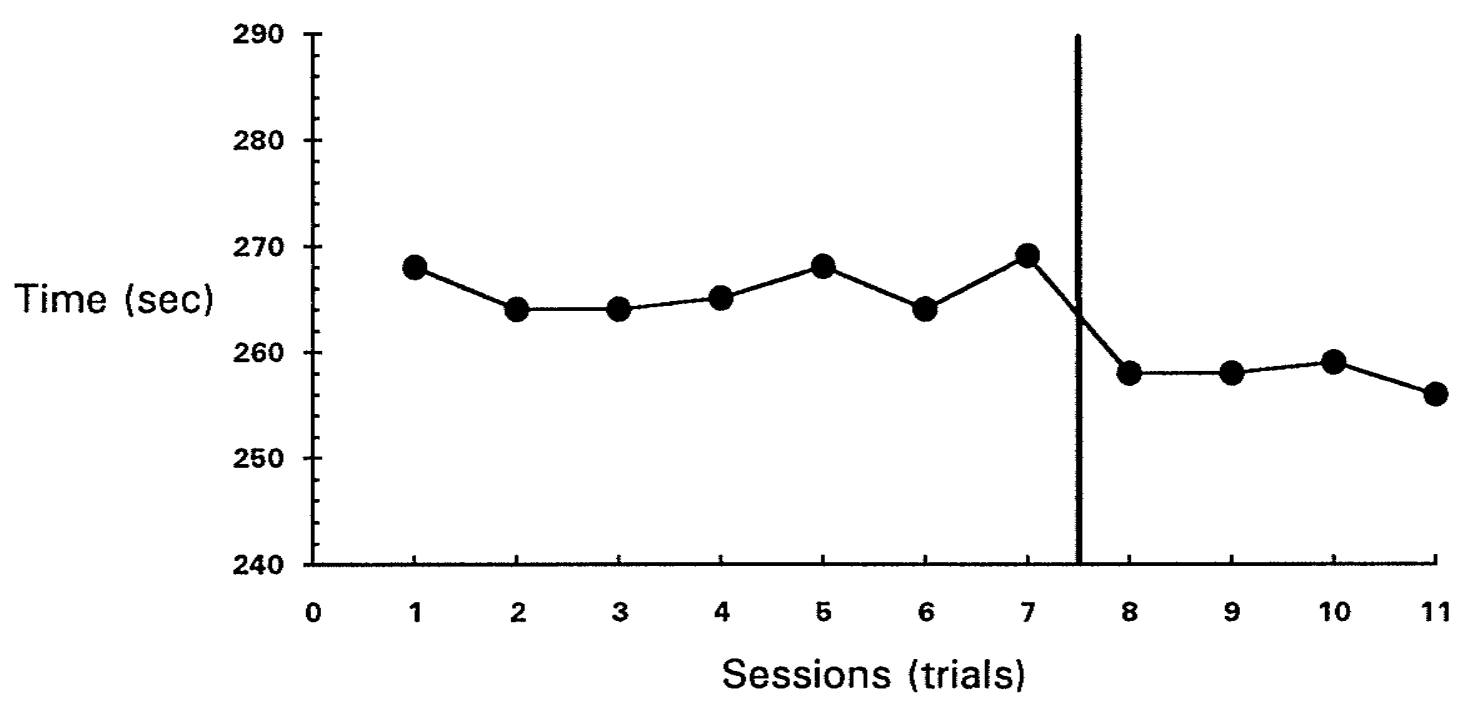

Figure 6. A graphical display of subject 3's 1600 metre running time. 


\section{Subject 3}

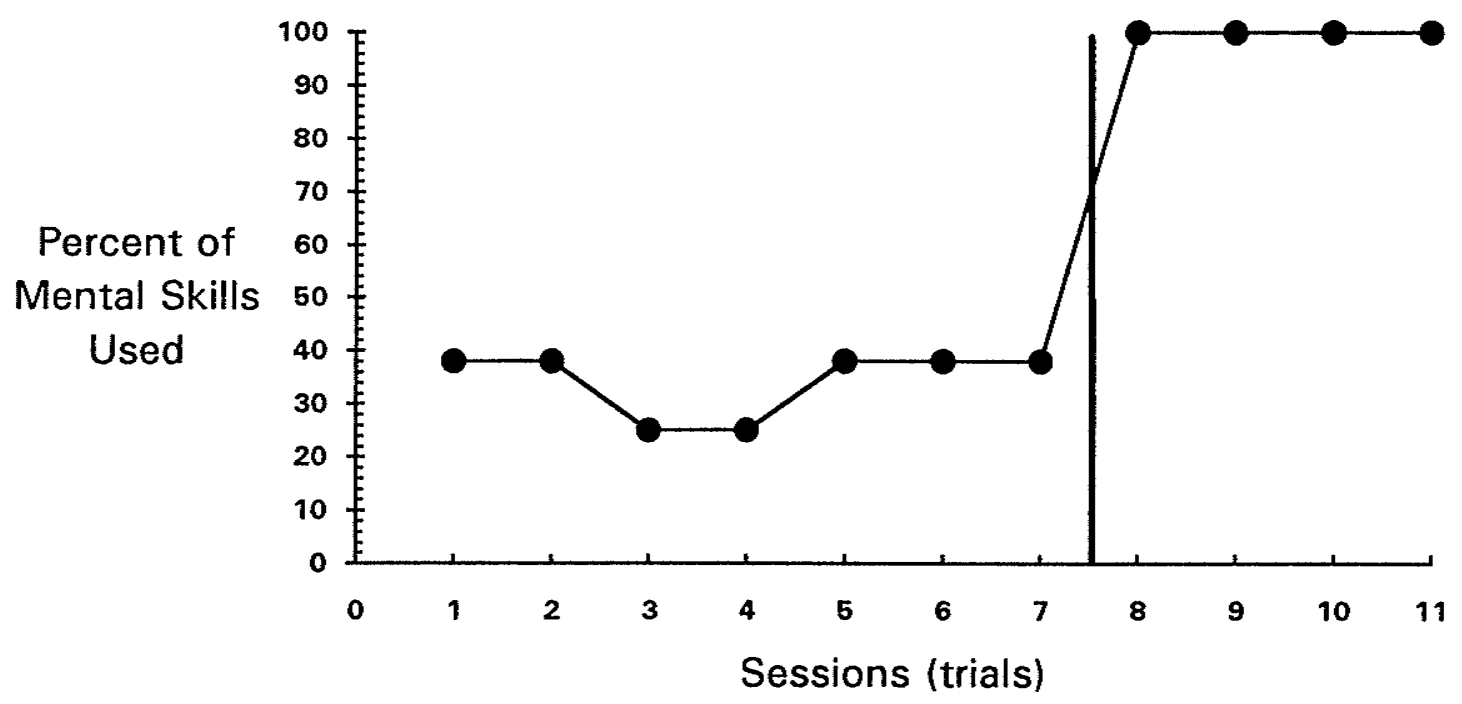

Figure 7. A graphical display of the percentage of mental skills utilized before and during the 1600 metre run. 
Subject 4

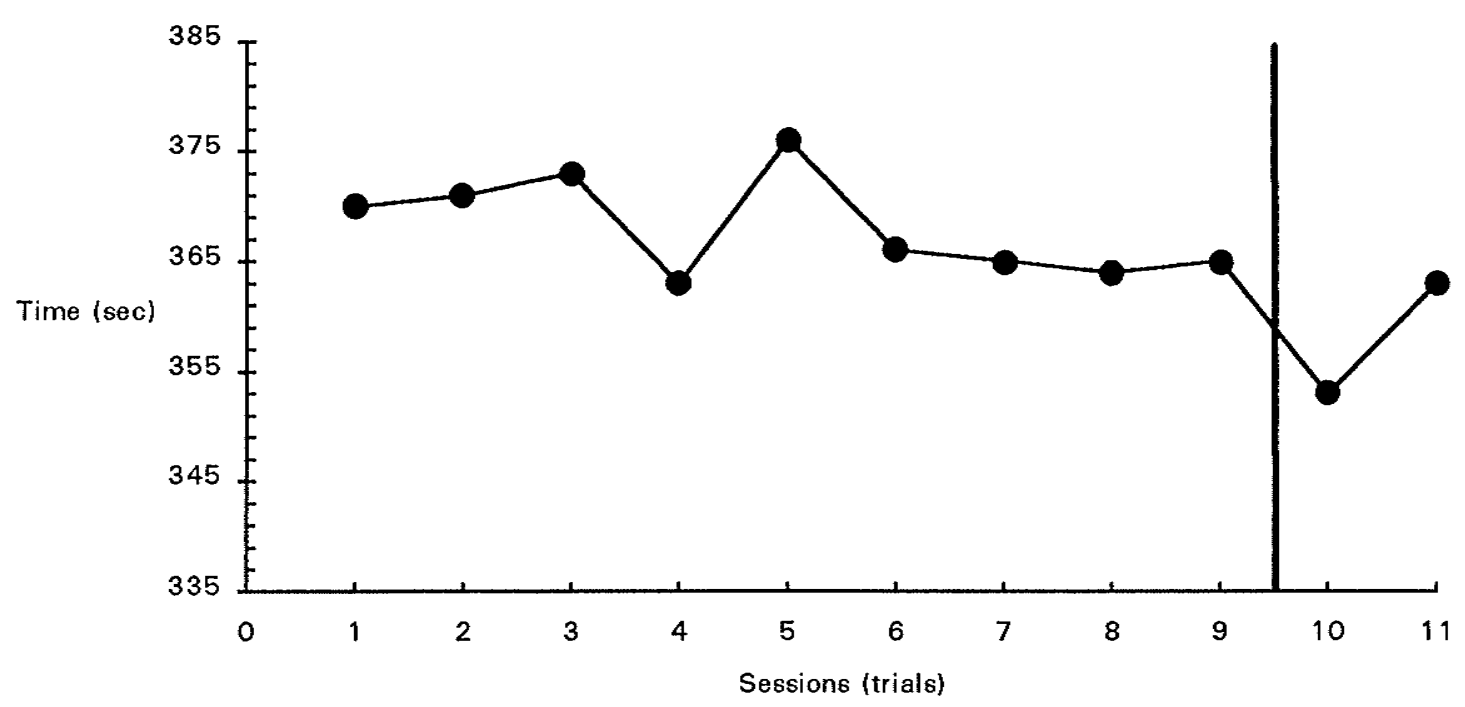

Figure 8. A graphical display of subject 4's 1600 metre running time. 


\section{Subject 4}

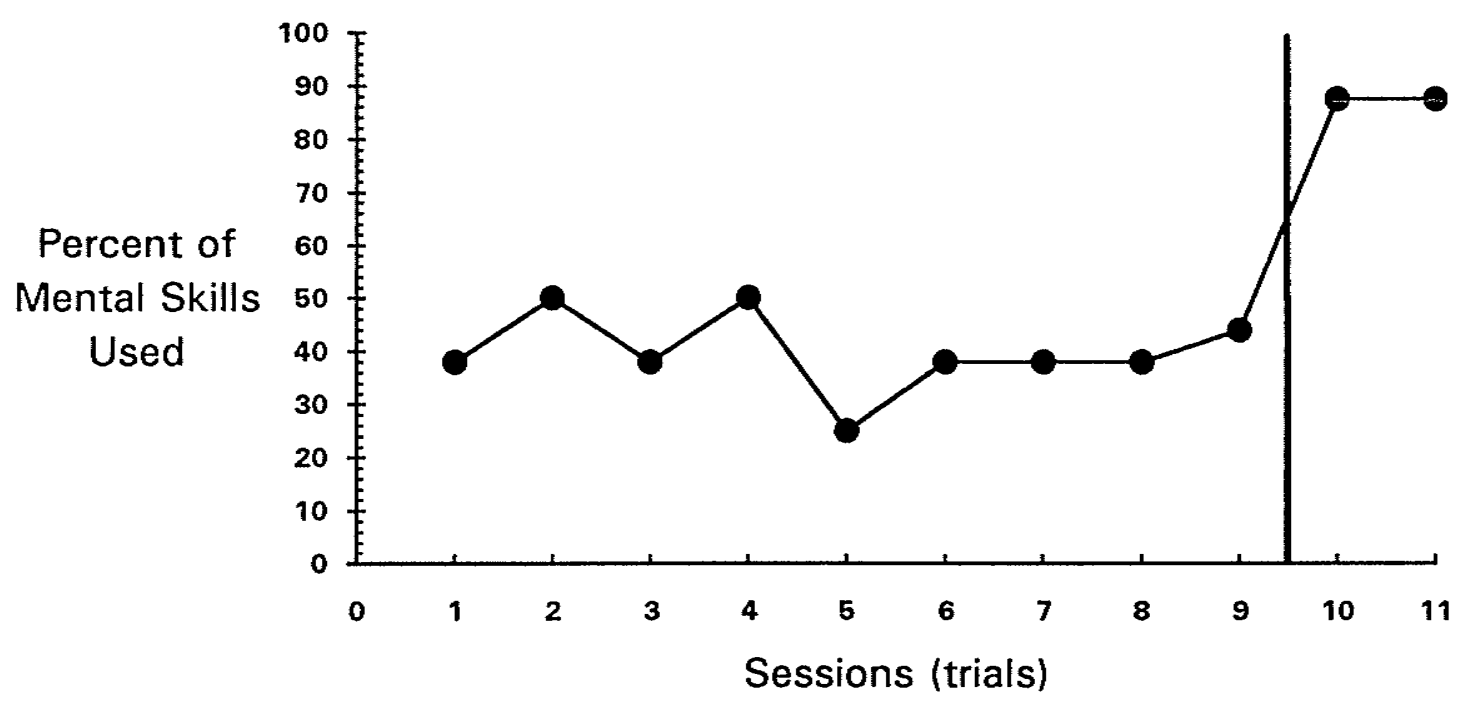

Figure 9. A graphical display of the percentage of mental skills utilized before and during the 1600 metre run. 
Social Validation

Each subject was asked to complete a social validation questionnaire (see appendix E) at the end of the study. Subject two and subject 4 reported that decreasing their 1600 metre time in practice was important. Subject I stated that it was somewhat important but that it was not a distance the subject would ever run in competition. subject 3 did not feel that decreasing the 1600 metre time in practice was as important as decreasing it in an actual competition. All four subjects felt it was either somewhat important or important to increase the consistency of their 1600 metre times in practice.

When asked how useful they thought the mental skills package utilized in this study was, 3 of the 4 subjects rated it as a 4 out of 5 , with subject 1 rating it a 5 out of 5 ("very useful"). Further, 3 of the 4 subjects reported that they found the mental skills package very enjoyable (i.e. rated it 5 out of 5 ). Subject 2 rated the enjoyment of the mental skills package as a 4 out of 5 .

When asked about their level of satisfaction with the results produced by utilizing the mental skills package, subjects 1 and 4 reported feeling very satisfied (rated it 5 out of 5), while subjects 2 and 3 rated it 4 out of 5 .

All of the subjects reported that they would continue to develop and use mental skills training in the future in both their training and at competitions and/or races. 
Social Validation by Coaches

To extend the social validation of the study, four local coaches were interviewed and asked to complete a questionnaire (appendix F). Three of the four coaches indicated that it was important to decrease an athlete's 1600 metre time in training (the fourth coach indicated that it was very important). The coaches also indicated that it was important to increase the consistency of an athlete's 1600 metre performance in training.

When asked whether they perceived the intervention results to be a significant improvement in the runner's times, all four coaches reported that the results were significant for the three subjects. Subject 3's results were perceived to be most significant because the subject was the highest performing athlete within the study. 


\section{Chapter 5}

Discussion

The present research demonstrated that the mental training package consisting of: imagery rehearsal, relaxation training, self-talk, and goal-setting was effective in improving the running performance of the subjects completing the 1600 metre distance. Martin and Pear (1992) indicate that one has greater confidence that an effect has been observed: the greater number of times that it is replicated; the fewer the overlapping data points between baseline and treatment phases; the immediacy of the effect after introduction of the intervention; the larger the effect in comparison to baseline; and the more consistent the findings are with the existing data and accepted theories.

Subject $I$ demonstrated the most convincing data. There was an immediate effect in comparison to baseline with no overlapping data points having been observed (see Figure 2). There was also a large difference in the level of performance in the intervention phase as compared to baseline.

There was a slight decline in performance observed in session nine. After this session, the subject reported experiencing physical discomfort in the abdominal area during the run. It is possible that this was responsible for the poorer performance during this session. 
Subject 3 also demonstrated a noticeable change in behavior. No overlapping data points were observed and the effect was immediate (see figure 6). Due to the ability level of subject 3 (elite national level runner), the demonstration of an effect is considerably more noteworthy as elite athletes are already performing at a very high level. This finding suggests that mental skills training can be effective with both elite and non-elite athletes. Subject 2 also demonstrated an effect immediately after introduction of the intervention. However, the first data point within the intervention phase does not fall below a previously achieved level of baseline performance (see figure 4). Although this overlapping data point may minimize the confidence of the effectiveness of the intervention, if one examines the graphical display of mental skills usage, the subject reports not utilizing mental skills training to its full potential (see figure 5).

subject 2 reported having difficulty controlling the imagery and producing the desired images in sessions six and seven which may have been responsible for the gradual improvement in performance. This observation is further supported in sessions eight through ten. In those sessions, subject 2's running times are the lowest while the mental skills usage scores are at their highest. This finding suggests, very strongly, that there is a relationship between a subject's level of performance and the utilization of mental skills training. 
During sessions five and six, subject 2 reported feeling the onset of a cold. It is possible that the subject's physical well being during those two sessions was not optimal and could, therefore, offer an explanation as to the poorer performance observed during the last session of the baseline phase, as well as the first session after the introduction of the intervention.

Although subject 4 was designated a control subject to account for any possible training effects, it was decided that, from an ethical point of view, it would be appropriate to deliver the intervention prior to the final two sessions, as no strong evidence of a training effect was apparent. Due to the fact that only two data points were available in the intervention phase for subject 4 , assessment is not warranted because there were not enough data points to evaluate a trend (Hersen \& Barlow, 1986).

Although an assessment cannot be made, it is important to discuss the possible explanations for a decline in performance during session eleven for subject 4 . Subject 4 changed his performance outcome goal prior to beginning their 1600 metre run on the last session. The new 1600 metre outcome goal was ten seconds faster from his time in session ten. After the second lap, subject 4 reported that he knew that the new time would not be attained and this thought demotivated the subject. It is possible that had the subject kept the performance outcome goal that was initially prepared for throughout the day, or if they had 
prepared a self-statement to deal with such an occurrence, they would have at maintained the new level of performance attained in the previous session (session ten).

Overall, an evaluation of the three experimental subjects performance throughout the study would suggest that each demonstrated a clear improvement in their running times at the 1600 metre distance and that one could be confident that the change in performance was due to the introduction of the mental skills training package. It is clear upon inspection of the graphical data that a relationship exists between their level of mental skills usage and their lowest 1600 metre running times. Further, this effect was repeated across three athletes which further supports the conclusion that the intervention was effective for improving performance.

Although there is no way of determining how much of the intervention effect was due to imagery rehearsal, the present study does support previous research in the area of mental imagery training on a running performance. Burhans, et al., (1988) demonstrated that running speeds were found to be superior over the initial four weeks of training for the internal (skills) imagery group relative to the control group. This is consistent with the findings of the present study which also found an effect over a four week period of time.

Another recent study (Bull, 1989) examined the effects of a visualization, self-talk, and relaxation package on the 
performance of an ultra-distance runner. Favorable results were reported with the one subject that was given the treatment in that study. The present study further supports the use of a mental training package with distance runners, however, the present study was able to repeat the effect across three subjects. An advantage of single-subject design methodology is that these designs commonly use three to five subjects and an important part of the design is demonstrating the efficacy of an intervention across subjects (Aeshleman, 1991).

Most of the studies examining the performance of distance athletes focused on the cognitive components in a mental training package. There was limited support within the literature to suggest that cognitive components alone were very effective in enhancing a distance runner's performance. The focus of the present mental training program was to ensure that behavioral components were employed to facilitate improved intervention effects (Martin \& Pear, 1992). The behavioral component was an essential part of the package and was implemented within the workbook (see appendix c) to not only facilitate the learning of the mental skills, but to aid in the athletes pre-training mental preparation.

Another area of importance within the present study was to put together as many component procedures as deemed necessary to obtain a total treatment success (Azrin, 1977). When designing the mental training package, it was decided 
that using the four most researched skills would be an effective way to equip each athlete with a "tool box" of mental skills that the athlete could utilize in a systematic manner before training and competitions.

The subjects also reported that using all of the skills in the package aided in the use of a single mental skill alone. When using a single mental skill such as relaxation, incorporating self-talk and imagery with one's relaxation training can facilitate a better relaxation experience. The inter-relatedness of the skills provided a more powerful intervention because the subjects were using the mental skills in conjunction with one another.

It is clear from the social validation questionnaire that the mental training package approach was received favorably by the athletes within the study. The athletes reported that they enjoyed the workbook approach to the introduction to mental skills training. They were also very satisfied with the results obtained. The results are a very important guideline for the athletes when evaluating the efficacy for utilizing mental skills in their training. The fact that a "package" of skills was used enhances the probability for an effect which in turn, encourages the athlete to incorporate the mental training into their regular training routines.

Positive competitive experiences were reported by subject $I$ and subject 4 after the study. Both experienced a personal best in their next triathlon and the subjects felt 
that the mental skills training was responsible for the favorable results attained. The subjects also reported that there performance had improved in their swimming and cycling both in training and in competition. Subject 2 and subject 3 had not participated in any competitions prior to the completion of the thesis, therefore, no information was available on any competitive experiences they may have had.

Another important aspect for the practical assessment of the intervention effects are the opinions of the coaches on whether the effects observed are considered significant. All of the coaches interviewed indicated that the results were significant for the three subjects. They reported that the results for subject 3, although not as large, were the most significant due to the high ability level of the athlete. The coaches indicated that although the mental training package was clearly responsible for the change in level of performance in subject 1 , some of the change may have resulted from simply providing a systematic, orderly method of training that may have been missing from the first subject's training routine.

The present study has also extended the literature relative to the appropriateness of utilizing single-subject designs when assessing the effectiveness of an intervention within the area of sport psychology (Zaichkowsky, 1980; Martin \& Hrycaiko, 1983; Wollman, 1986; Bryan, 1987). Although single-subject designs have been used in the past to determine the effectiveness of an intervention on a sport 
performance, none to date have investigated the efficacy of using a mental training package in an endurance performance. Most of the successful studies have involved open and closed physical behaviors (e.g. Kendall, et al., 1990; wolko et al., 1993; McKenzie \& Liskevych, 1983).

Another characteristic of single-subject designs is the use of the repeated measurement of the main dependent variable throughout the duration of the study. This approach permitted the assessment of important aspects of the subjects' running performances across many sessions. The assessment included an inspection of the quantity and quality of the imagery and the cognitions and affects of the subjects throughout the experiment. Wollman (1986) indicated that this may be important in order to help determine whether certain types of thoughts, attitudes, and feelings were helpful in achieving a successful performance. An element that is difficult to control in any study is the Hawthorne effect. The Hawthorne effect refers to the subject's experiencing an improvement in performance merely due to the fact that the subject is participating in a study (Drew, 1976). In single-subject design, the length of the intervention phase helps to control this possible explanation for an immediate effect. As seen in Figure 1, the intervention effects for the three experimental subjects did not dissipate over time. 
The overall results of this study indicate that a mental training package consisting of imagery rehearsal, relaxation training, self-talk, and goal-setting enhanced the endurance performance of the three subjects. This study effectively extended the literature on both the efficacy of using mental training to enhance an endurance performance as well as the efficacy for utilizing single-subject research design to assess the effect of an intervention on an athlete's performance. Finally, the intervention used and the results obtained received a favorable social validation assessment, both from the subjects and from the coaches. 
Recommendations

1. It is recommended that future research investigate the effects of a mental training package on the endurance performance of an athlete in actual competitive situations. Both coaches and athletes identify that improvement in practice is important, but it is in competition that the true benefits of utilizing mental skills training needs to be researched.

2. The effects of the intervention in the present study was observed for three weeks for the first subject. An extended assessment period (intervention phase) should be carried out to determine if an improvement in performance can be continued to be observed, and to provide extended intervention phases for the remaining subjects.

3. An emphasis on the utilization of a mental training package utilizing a combination of mental skills should be continued. Although research investigating the efficacy for using a single mental skill to improve performance (i.e. imagery or relaxation) is a necessary addition to the body of knowledge in this research area, the package approach lends itself to possessing more practical benefits in the long run for the subjects (athletes) within a field study. 
4. Additional qualitative information needs to be collected in future research to aid in the assessment of the observations. Qualitative information pertaining to the efficacy for utilizing each specific mental skill and their inter-relatedness should be also be obtained. 
References

Andre, J., \& Means, J. (1986). The rate of imagery in mental practice: An experimental investigation. Journal of Sport Psychology, 8, 124-128.

Aeschleman, S.R. (1991). Single-subject designs: Some misconceptions. Rehabilitation Psychology, 36, 43-49. Azrin, N.H. (1977). A strategy for applied research: Learning based but outcome oriented. American Psychologist, 32, 140-149.

Botterill, C. (Speaker) (1987). What you see is what you get [Videotape]. Ottawa: Coaching Association of Canada.

Bryan, A.J. (1987). Single-subject designs for evaluation of sport psychology interventions. The sport Psychologist, 1, 283-292.

Bull, S.J. (1989). The role of the sport psychology consultant: A case study of ultra distance running. The Sport Psychologist, 3(3), 254-264.

Bunker, L., Williams, J., \& Zinsser, N. (1993). Cognitive techniques for improving performance and building confidence. In J.M. Williams (Ed.), Applied Sport Psychology, 2nd ed. (pp. 225-242). Mountainview, CA: Mayfield Publishing Co.

Burhans, R., Richman, C., \& Bergey, D.B. (1988). Mental imagery training: Effects on running speed performance. International Journal of Sport Psychology, 19(1), 26-37. 
Daw, J., \& Burton, D. (1994). Evaluation of a comprehensive psychological skills training program for collegiate tennis players. The Sport Psychologist, 8(1), 37-57.

Drew, C.J. (1976). Introduction to designing and conducting research. St. Louis: C.V. Mosby.

Erbaugh, S.J., \& Barnett, M.L. (1986). Effects of modeling and goal-setting on the jumping performance of primarygrade children. Perceptual and Motor Skills, 63(3), 1287-1293.

Feltz, D.L. \& Landers, D.M. (1983). The effects of mental practice on motor skill learning and performance: A meta-analysis. Journal of Sport Psychology, 5, 25-57. Gill, D.L. (1986). Psychological Dynamics of Sport. Champagne, IL. Human Kinetics Publishers, Inc. Gould, D. (1993). Goal-setting for peak performance. In J.M. Williams (Ed.), Applied Sport Psychology, 2nd ed. (pp. 158-169). Mountainview, CA: Mayfield Publishing Co.

Greenspan, M.J., \& Feltz, D.F. (1989). Psychological interventions with athletes in competitive situations: A review. The sport Psychologist, 3(3), 219-236.

Hall, C., \& Rodgers, W. (1989). Enhancing coaching effectiveness in figure skating through a mental skills training program. The sport Psychologist, $\underline{3}(2), 142-$ 154. 
Hal1, H., Weinberg, R., \& Jackson, A. (1987). Effects of goal specificity, goal difficulty, and information feedback on endurance performance. Journal of sport Psychology, $9(1), 43-54$.

Hamilton, S.A., \& Fremouw, W.J. (1985). Cognitivebehavioral training for college basketball free throw performance. Cognitive Therapy and Research, 9, 479483.

Harris, D.V. \& Williams, J.M. (1993). Relaxation and energizing techniques for regulation of arousal. In J.M. Williams (Ed.), Applied Sport Psychology, 2nd ed. (pp. 185-199). Mountainview, CA: Mayfield Publishing Co.

Hazen, A., Johnstone, C., Martin, G., \& Srikameswaran, S. (1990). A videotaping feedback package for improving skills of youth competitive swimmers. The sport Psychologist, 4(3), 213-227.

Hersen, M., \& Barlow, D. (1976). Single-case experimental designs: Strategies for studying behavior change. N.Y.: Pergamon Press. Hume, K.M., Martin, G.L., Gonzalez, P., Cracklen, C., \& Genthon, S. (1985). A self-monitoring feedback package for improving freestyle figure skating practice. Iso-Ahola, S.E. (1992) Mental training. Medicine in sports Training and Coaching, 35, 215-234. 
Jackson, S. \& Roberts, G. (1992). Positive performance states of athletes: Toward a conceptual understanding of peak performance. The Sport Psychologist, 6 , 156171.

Kazdin, A.E. (1992) Research Design in Clinical Psychology. New York, N.Y.: Macmillan Publishing Company Kendall, G., Hrycaiko, D., Martin, G.L., \& Kendall, T. (1990). The effects of an imagery rehearsal, relaxation, and self-talk package on basketball game performance. Journal of Sport and Exercise Psychology, 12, $157-166$.

Kenitzer, R., \& Briddell, W. (1991) Effect of mental imagery strategies on swimming performance. Applied Research in Coaching and Athletics Annual, March 259273.

Kirschenbaum, D. \& B Bale, R. (1984). Cognitive-behavioral skills in sports: Application to golf and speculations about soccer. In W.F. Straub \& J.M. Williams(Eds.), (1984) Cognitive Sport Psychology. Lansing, New York:

Sport Science Associates. 275-288.

Landers, D. M. (1992). What sport psychology can contribute to the enhancement of human performance. In $R$. Christina \& H. Eckert (Eds.), Enhancing Human Performance in sport. (pp. 104-116). Champagne, IL. Human Kinetics Publishers, Inc. 
Li-Wei, z., Qi-Wei, M., Orlick, T., \& Zitzelsberger, L. (1992). The effect of mental-imagery training on performance enhancement with 7-10 year old children. The Sport Psychologist, $6(3), 230-241$.

Locke, E.A. \& Latham, G.P. (1985) The application of goalsetting to sports. Journal of Sport Psychology, 7, 205222 .

Mahoney, M.J., Gabriel, T.J., \& Perkins, T.S. (1987). Psychological skills and exceptional athletic performance. The sport Psychologist, 1,181-199.

Mahoney, M.J. \& Avener, M. (1977). Psychology of the elite athlete: An exploratory study. Cognitive Therapy and Research, 1, 135-141.

Martin, G.L., \& Hrycaiko, D. (1983). Principles and procedures of applied behavior analysis with illustrations from sport and physical education. In G.L. Martin \& D. Hrycaiko (Eds.) Behavior modification and coaching: Principles, procedures, and research. (pp. 21-45). Springfield, IL: Charles C. Thomas Martin, G.L., \& Lumsden, J. (1987). Coaching: An Effective Behavioral Approach. St. Louis, Missouri, Times Mirror/Mosby College Publishing.

Martin, G.L. \& Pear, J. (1992) Behavior Modification: What it is and how to do it 4 th ed. Englewood Cliffs, N.J. Prentice-Hall, Inc. 
McKenzie, T.L., \& Liskevych T.N. (1983). Using the multielement baseline design to examine motivation in volleyball training. In G.L. Martin \& D. Hrycaiko (Eds.) Behavior modification and coaching: Principles, procedures and research. Springfield, IL: Charles C. Thomas, 203-212.

Okwumabua, T.M., Meyers, A.W., Schleser, R., \& Cooke, C. (1983) Cognitive strategies and running performance: An exploratory study. Cognitive Therapy and Research, 7. $363-370$.

Orlick, T. (1986). Psyching For Sport: Mental Training for Athletes. Champagne, IL. Leisure Press. Orlick, T. \& Partington, J. (1988). Mental links to excellence. The sport Psychologist, 2, 105-130 Rodgers, W., Hall, C., \& Buckolz, E. (1991). The effect of an imagery training program on imagery ability, imagery use, and figure skating performance. Journal of Applied Sport Psychology, 3, 109-125.

Rotella, R.J., Gansneder, B., Ojala, D., \& Billing, J. (1980). Cognitions and coping strategies of elite skiers: An exploratory study of young developing athletes. Journal of Sport Psychology, 2(4), 350-354. Rushall, B. (1979). Psyching in Sports. London: Pelham. Rushall, B. (1984). The content of competition thinkings. In W.F. Straub \& J.M. Williams (Eds.), Cognitive Sport Psychology. (pp. 51-61). Lansing, N.Y.: Sport Science Associates. 
Rushall, B. (1989). Sport Psychology: The key to sporting excellence. International Journal of Sport Psychology. 20, $165-190$.

Rushall, B., Hall, M., Roux, L., Sasseville, J., \& Rushall, A. (1988). Effects of three types of thought content instructions on skiing performance. The sport Psychologist, 2 (4), 283-297.

Salmon, J., Hall, C. \& Haslam, I. (1994). The use of imagery by soccer players. Journal of Applied Sport Psychology, 6, 116-133.

Silva, J.M. (1982). Performance enhancement through cognitive intervention. Behavior Modification, $\underline{6}(4)$, $443-463$.

Silva, J.M. \& Appelbaum, M.I. (1989). Associationdissociation patterns of United States Olympic marathon trial contestants. Cognitive Therapy and Research, $13(2), 185-192$.

Straub, W.F. (1989). The effect of three different methods of mental training on dart throwing performance. sport Psychologist, $3(2), 133-141$.

Suinn, R.M. (1977). Behavioral methods at the winter Olympic games. Behavior Therapy, $8,283-284$. Vealy, R.S. (1988). Future directions in psychological skills training. The sport Psychologist, 2(4), 318-336. 
Weinberg, R.S., Seaborne, T., \& Jackson, A. (1981) Effects of visuo-motor behavior rehearsal, relaxation, and imagery on karate performance. Journal of Sport psychology, $3,228-238$.

Weinberg, R.S., Smith, J., Jackson, A., \& Gould, D. (1984). Effect of association, dissociation, and positive selftalk strategies on endurance performance. Canadian Journal of Applied Sport Sciences, 9, 25-32 .

Weinberg, R.S. \& Williams, J.M. (1993). Integrating and implementing a psychological skills training program. In J.M. Williams (Ed.), Applied sport Psychology, 2nd ed. (pp. 274-298). Mountainview, CA: Mayfield Publishing Co. Wrisberg, C.A. \& Anshel, M.H. (1989). The effect of cognitive strategies on the free throw shooting performance of young athletes. The sport Psychologist, $\underline{3}(2), 95-104$.

Wolf, M.M. (1978), Social validity: The case for subjective measurement or how applied behavior analysis is finding its heart. Journal of Applied Behavior Analysis, 11, 203-214.

Wolko, K.L., Hrycaiko, D.W., \& Martin, G.L. (1993). A comparison of two self-management packages to standard coaching for improving practice performance of gymnasts. Behavior Modification, 17(2), 209-223. 
Wollman, N. (1986). Research on imagery and motor performance: Three methodological suggestions. Journal of Sport Psychology, 8, 135-138.

Zaichkowsky, L.D. (1980). Single-case experimental designs and sport psychology research. In C.H. Nadeau, W.R. Halliwell, K.M. Newell, \& G.C. Roberts (Eds.) Psychology of motor behavior and sport - 1979 (pp. 171-179). Champaign, IL.: Human Kinetics.

ziegler, S.G. (1987). Effects of stimulus cueing on the acquisition of ground strokes by beginning tennis players. Journal of Applied Behavior Analysis, 20, $405-411$. 
61

Appendices 


\section{(Appendix A) \\ Lap Number Recording Sheet 1600 metre}

Date:

Time:

Session Number

Instructions: Record the lap interval time for each subject as they complete each lap. Record the final time in the space provided upon completion of the fourth lap.

Subject No. Name:

Subject No.

Name:

Subject No. Name:

Subject No. Name:

Subject No. Name:

$\begin{array}{ll}\text { Lap } 1 & \text { Lap } 3 \\ \text { Lap } 2 & \text { Lap } 4\end{array}$

Lap Times

$\begin{array}{ll}\operatorname{Lap} 1 & \text { Lap } 3 \\ \text { Lap } 2 & \text { Lap } 4\end{array}$

Lap Times

Lap 1

Lap 2

Lap 2

Lap Times

Lap 1
Lap 2
Lap 1
Lap 2

Lap 3

Lap 4

Lap 3

Lap 4

Lap 4

Lap 3

Lap 4

Observer/Experimenter Comments: 
(Appendix B)

\section{Mental Skills Assessment}

(After each run, complete the following questionnaire.)

Name:

Date:

Yes No

1. Did you perform a relaxation technique before your run?

e.g. centering when stretching to be mentally calm and/or physically relaxed

2. Did you use a relaxation strategy during your run?

e.g. used self statements and/or centering to maintain a relaxed and loose mental and/or physical state

3. Did you mentally rehearse before you went for your run?

4. Did you use imagery in any way during your run?

5. Did you perform any self-statements during your warm-up?

6. Did you use positive self-talk or coping self-statements during the run?

7. Did you set any goals (personal or performance) before your run?

8. Did you have a particular mental skill(s) goal for today's run?

Percent of total mental skills used:

$\frac{(\text { Yes) total }}{8} \times 100=\frac{}{8} \times 100=$

(Please circle the appropriate number)

How much effort did you expend on today's run?

No effort at all

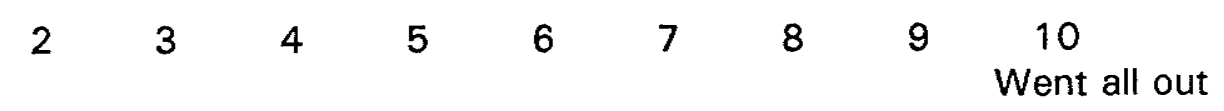


(Appendix C)

\section{Using Mental Skills \\ For Performance Enhancement.}

by Thomas Patrick

University of Manitoba 


\title{
Skill 1 Relaxation (Emotion Control)
}

\author{
(adapted from Suinn's Seven Steps to Peak Performance)
}

Being able to relax the body gives the athlete control over muscles important for keeping loose in competition. The feeling of "flow" is often associated with being loose and effortless. Knowing how to relax can also be used if the competition or conditions elicit feelings of anxiety or tightness. Finally, relaxation can be a building block for other mental skills training such as imagery and self statements (self-talk).

\section{Step 1.1 Progressive Muscle Relaxation Training}

Progressive relaxation involves the tensing of muscles (or muscle groups), focusing on how that feels, and then releasing the tension (relaxing the muscle). In order to develop your relaxation, you should perform the following sequence of behaviors. Complete three to four trials within a two day period and select a location that is quiet and free of distractions.

Note: Tense each muscle or muscle group only as long as is required for you to notice the tension generated, then relax that muscle or muscle group. Perform each sequence of tensing/relaxing twice. It is important to keep your eyes closed during the session, if possible. This will improve your ability to attend to the muscles within your body.

- Begin with the dominant hand - clench into a fist, notice the tension, release, and notice the contrasting relaxation feeling.

- Tense the other hand into a fist, then relax.

- Flex the right arm to tighten the biceps, then relax.

- Flex the other arm, relax.

- Raise your eyebrows and frown to tense the forehead, relax.

- Shrug the shoulders for tension, relax.

- Take a deep breath, hold it to tense; slowly exhale and notice the relaxation. Do it again.

- Tighten your stomach muscles, relax.

- Point your toes downward to tense, relax.

- Now, take a slow deep breath, drawing in the air by your stomach moving outward; slowly exhale by your stomach moving inward.

- Repeat this deep breathing process 3 times. Center your attention on this breathing process (will be referred to as "centering" later on)

- Return to normal breathing

\section{Suggestion:}

Using a walkman or appropriate source of music that you find relaxing may be helpful when attempting progressive relaxation on your own. 
Step 1.2 Centering While Stretching Before Competition

The second step involves shortening the time required to reach a relaxed state using the centering breathing technique. As you stretch each muscle or muscle group before competition, use deep centering breaths to feel the muscle stretch farther and farther upon each breath. This process should take about 5-10 minutes (or be completed within your normal stretching time allotted). It is best to perform this within the environment that closely approximates the actual competitive situation that will exist just before your competition.

\section{Centering/stretching process}

- First, focus your attention on centered breathing: remember that your stomach should move outward when you inhale, and inward when you exhale. Take 3 deep breaths, breathing into your diaphragm, and lowering your center of gravity with each breath.

- Now stretch the first desired muscle group. As you hold the stretch, take your first centering breath and feel the muscle stretch farther. Repeat this two more times feeling the muscle stretch farther and farther with each breath.

- Next, release the tension and recognize the relaxed feeling of that muscle.

- Repeat this cycle until you have stretched the entire body.

- Depending on your normal stretching routine, stretch the entire body 3 times consecutively. This number is solely dependent on the individual's preference.

\section{Step 1.3 Relaxing During Competition}

In the previous two steps, you have become more aware of your body's feelings. This is important in order to achieve relaxation within less and less time. The goal is to achieve relaxation as quickly as possible within the competitive situation. This can be done by incorporating the techniques learned in the previous two steps.

\section{Relaxation during the race (competition)}

- First, take 3 deep centering breaths.

- Next, focus on the muscle group(s) that are tense and while taking a centering breath, feel the muscle relax and become loose.

- Repeat as necessary until you've attained a relaxed state again.

\section{Suggestions:}

Implement this into your regular training sessions. It will require several sessions before you are able to achieve a relaxed state within the race. After each practice or competition, recall occasions where you were tense and whether you were able to achieve a relaxed state again. A post competition evaluation questionnaire will be provided for you at the end of this manual. 


\section{Training Journal For Relaxation Exercises}

For each practice session of each skill within the relaxation component (specifically for steps 1.1 and 1.2), record the date and time, and also the level of tension before the relaxation session and the level after the session.

Use a number between 0 and 10 that corresponds to your perception of your tension level from the scale described below. The two extremes have been indicated to assist in your interpretation of your tension level. Be as accurate as possible
$0 \quad 1$
2
34
5
6
7
89
10

Mentally calm

Physically loose

Mentally uptight

No worries

Overall relaxed

Tensed muscles

Severely worried

Overall tense

Progressive Muscle Relaxation (Step 1.1)

\begin{tabular}{|c|c|c|}
\hline Date of Practice & $\begin{array}{c}\text { Level of Tension } \\
\text { Before Relaxation }\end{array}$ & $\begin{array}{c}\text { Level of Tension } \\
\text { After Relaxation }\end{array}$ \\
\hline & & \\
\hline & & \\
\hline & & \\
\hline & & \\
\hline
\end{tabular}

Centering While Stretching (Step 1.2)

\begin{tabular}{|c|c|c|}
\hline Date of Practice & $\begin{array}{c}\text { Level of Tension } \\
\text { Before Relaxation }\end{array}$ & $\begin{array}{c}\text { Level of Tension } \\
\text { After Relaxation }\end{array}$ \\
\hline & & \\
\hline & & \\
\hline & & \\
\hline & & \\
\hline
\end{tabular}




\title{
Skill 2 Imagery (Mental Rehearsal)
}

\author{
(adapted from Suinn's Seven Steps to Peak Performance)
}

Top athletes in any sport have developed an excellent capacity for clear, vivid imagery and use this skill extensively. In well developed imagery, you do not merely see the image, you experience a feeling or recall an experience through the image. When you create or recall an image in your mind, you should attempt to enter fully into that image with all your senses. Above all else, you must "feel" what you are doing (Orlick, 1986).

\section{Step $2.1 \quad$ Initial Imagery Training}

- Pick a quiet place and time, and sit or lie down comfortably.

- Use centering to achieve a relaxed state.

- Close your eyes (you may leave them open but it is easier initially to mentally rehearse with them closed).

- Switch to a scene of a familiar activity or situation that is relaxing for you (lit can involve a physical activity but it doesn't have to). It should be of a skill/activity that you have already completed successfully.

- Let the scene develop, allowing yourself to be there and using any senses that make the experience real for you. Don't try to force the scene; as details appear, use them to help the rest of the scene.

- As you experience this relaxing scene, use it to further increase your relaxation. Retain the scene for 30 seconds or so.

- Now switch the scene off and return to centering.

- Switch on the scene again. Retain it and be there in the scene for about 30 seconds. Then turn it off again and return to centering

- Repeat the sequence once more.

- End the training session by opening your eyes.

\section{Suggestions:}

Repeat this step once daily for at least 3 consecutive days. When mentally rehearsing (imaging), keep in mind some important factors:

- imagine each situation to a successful conclusion (always a positive outcome)

- focus primarily on factors within your control (not on the win or loss etc.)

- the images should be in "real time", do not imagine in a speed other than how you would actually perform a skill and/or motion

- attend to as many sensory sources as possible (sight, sound, taste, smell, and especially feel)

- use imagery whenever you have time in many different situations

- you may adopt an internal focus (through your eyes) or an external one (looking at yourself as if you were looking at another person) 
After step 2.1, you should be able to use centering and imagery to visualize various relaxation scenes. You should not proceed to step 2.2 until your relaxation scenes are consistently vivid and realistic. In step 2.2, you will be performing imagery that is specific to the actual competition. Always imagine successful competition scenes only! What you see is usually what you get.

Depending on your sport and related performance factors to that sport/activity, select some important performance goals that will facilitate a successful performance. These can be general images such as seeing and feeling yourself relaxed, fluid and fast when running your race. Or, they can be specific images such as seeing and feeling yourself react positively under pressure (perhaps being passed by another competitor, or coping with psych-out attempts by an opponent).

It will be up to you to decide what images will be of most help to your activity and/or situation. There may be some images that you will want to program into your pre-competition sequence, and there will be some that will be pertinent for one specific situation/competition alone. When thinking about the upcoming competition, select some areas/goals that you need to focus on and identify them to be mentally rehearsed during your imagery session. Be creative and use imagery as much as you can in order to help you prepare and perform to your potential.

\section{Competition Specific Imagery}

- Within the competition environment, use centering to achieve a relaxed state.

- First visualize a relaxation scene. Be in it for about 30 seconds.

- Switch off the scene and continue to use centering to maintain the level of relaxation.

- Now see yourself performing successfully a skill and/or relevant behavior that you have selected to be of importance before the competition.

- See and feel the scene as if it were actually happening right at that moment and you were a participant within it.

- Continue to visualize the scene until it has come to an end (do not end it early).

- Once it has finished switch off the scene and return to centering.

- Repeat the entire process (excluding the relaxation scene) until you have thoroughly visualized the competition and all of the important components that you have identified prior to the session.

\section{Suggestions:}

Practice this process (step 2.2) frequently in training sessions and master the ability to mentally rehearse before using it at a competition. You must be in control of your images (ensure the images are task related). Use the training journal to keep track of your imagery training sessions and monitor the content and quality of each session. Remember that it is a skill much like any other physical skill that you will have learned in the past. It will require consistent practice for you to master the ability to visualize. 


\section{Initial Imagery Training (Step 2.1)}

For each session rate yourself on the following scales. If after session 3 your relaxation image(s) are not realistic, vivid, and under control then continue with more sessions until this has been achieved.

\section{Session 1}

Rate your level of relaxation at the end of the session, with $10=$ extremely tense and $0=$ extremely relaxed:
$0 \quad 1$
23
4
5
$6 \quad 7$
$8 \quad 9 \quad 10$

Rate how vivid and realistic your relaxation image was, with $0=$ not real at all, and 10 = very real, felt $\mid$ was there participating:
$0 \quad 1 \quad 2$
3
45
6
78
$9 \quad 10$

\section{Session 2}

Rate your level of relaxation at the end of the session, with $10=$ extremely tense and $0=$ extremely relaxed:
$0 \quad 1$
23
4
5
$\begin{array}{ll}6 & 7\end{array}$
8
$9 \quad 10$

Rate how vivid and realistic your relaxation image was, with $0=$ not real at all, and 10 = very real, felt I was there participating:
$\begin{array}{lll}0 & 1 & 2\end{array}$
3
45
$\begin{array}{ll}6 & 7\end{array}$
8
$9 \quad 10$

\section{Session 3}

Rate your level of relaxation at the end of the session, with $10=$ extremely tense and $0=$ extremely relaxed:
$0 \quad 1$
23
4
5
$\begin{array}{lll}6 & 7 & 8\end{array}$
$9 \quad 10$

Rate how vivid and realistic your relaxation image was, with $0=$ not real at all, and 1 - = very real, felt I was there participating:
$0 \quad 1$
23
4
5
6
7
8
$9 \quad 10$ 


\section{Competition Specific Imagery Training (Step 2.2)}

Answer the following questions after each imagery session before competition until you have mastered the skill of mental rehearsal. Your score should be consistently high within the practice/training situation before you try to use it in an actual competition.

1. When you were trying to picture something mentally, how much difficulty did you have in getting the image to do what you wanted it to do? That is, was it easy or difficult for you to control your mental images?

$\begin{array}{ccccccccccc}0 & 1 & 2 & 3 & 4 & 5 & 6 & 7 & 8 & 9 & 10 \\ \text { Very difficult } & & & & & & & & \end{array}$

2. When you picture something mentally, how vivid or clear are your mental images?

Not at all clear

$\begin{array}{llllllllll}0 & 1 & 2 & 3 & 4 & 5 & 6 & 7 & 8 & 9 \begin{array}{c}10 \\ \text { Very clear }\end{array}\end{array}$

3. When you use imagery, how strong are the feelings or sensations associated with your imagery?

No feeling
$0 \quad 1$
23
45
$6 \quad 7$
8
910

Strong feeling

4. About how many time did you "see" and /or "feel" yourself running through your event (or parts of it) in imagery?

None

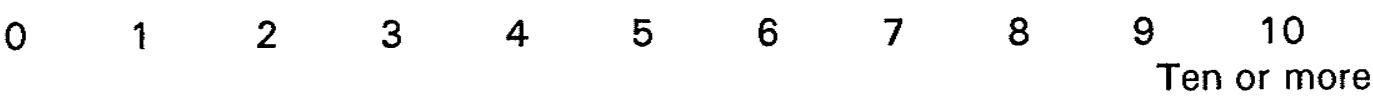




\title{
Skill 3 Self-talk
}

\author{
(adapted from Suinn's Seven Steps to Peak Performance)
}

Your self-statements or thoughts directly affect feelings and ultimately your actions. Inappropriate or misguided thinking usually leads to negative feelings and poor performance, just as appropriate or positive thinking leads to enabling feelings and good performances. Our thoughts (self-talk) can serve as cues to prompt certain desirable behaviors to occur when required. They can also be used as a component of emotion control (when relaxing or trying to energize).

Successful and unsuccessful competitors are subject to negative thoughts. Although it is desirable to keep your self-talk positive, there is no way to escape all of your negative thoughts. Acknowledge the negative thoughts.

\section{Step 3.1 Constructing Appropriate Self-talk}

There are some important factors to consider when using self-talk:

- The self-talk should be positive and constructive le.g. You say to yourself "I'm getting tired and cramped". An appropriate reaction to this statement would be "Just take a centering breath, relax, and go for it. I'm going to finish strong").

- The self-statement should provide relevant information. It should identify what you will do, how you will do it, and why you will do it. Avoid one word statements such as "hustle", or "push" until a more precise statement has been identified and utilized extensively first.

- Keep your self-talk focused on factors within your control. It must be realistic and focus on the process not the outcome. (e.g. Avoid a statement such as "I'm going to win". A more appropriate statement would be "I'm going to give my strongest effort so that there is nothing left at the end" and "I'll keep my stride powerful and be ready when the lead pack takes off".

- Self-talk has to be learned and practiced. Practice it extensively and in a variety of situations when training before applying it to competition. Especially use it in conjunction with the other mental skills (imagery, relaxation, and goal setting).

- Experiment using self-statements aloud to yourself (overtly) or silently to yourself (covertly). Determine which is most effective and use that technique.

- For endurance events, your self-talk should consist largely of self-statements that focus on technique and emotion control.

- Use it extensively before a competition (or practice) while visualizing a successful performance. Use statements such as "I'm confident", or "I'm ready" to foster feelings of self confidence and feeling positive.

Note:

Refer to the self-talk exercises on page 10 and work through them in order to develop your skill at composing and implementing positive self-talk. 
Step 3.2 Controlling Negative Thoughts/Self-Statements

Using negative thoughts or self-statements in a positive way

Use the negative thought to act as a cue for you to implement a reactive strategy. There are 3 components to this routine:
i. RELAX
ii. REGROUP
iii. REFOCUS

First relax by performing a deep centering breath, and attend to muscles that may be tense. Once you have relaxed, then start to regroup by putting the situation in perspective. Rehearse a self-statement that will relieve the situation that prompted the negative self-statement. For example, if you respond "Oh no, I'm falling away from the pack again" counteract that statement by using a more positive self-instruction such as "That's okay, just stick to your race, you're doing fine".

Finally, you'll need to refocus on what it is you have to do next. Perhaps you need to keep the lead pack within an acceptable distance. A self statement such as "I can push harder and stay with them. Go for it, that's why I'm here" may be appropriate.

Note:

Refer to page 11 and complete the training plan exercises. This will assist you in incorporating self-talk during your training and in competition. 
Self-talk Exercises (Step 3.1)

List positive self-statements that will be helpful to you before and during competition (or practices). Carefully consider all of the points discussed in section 3.1 (page 8 ) and implement as many of them as you can into your self-talk. Indicate on the right of the self-statement when it would be an appropriate situation to use each self-instruction that you have composed.

\begin{tabular}{|c|c|}
\hline $\begin{array}{c}\text { Positive Self Statement To Be } \\
\text { Rehearsed }\end{array}$ & $\begin{array}{c}\text { Time Used Before/During } \\
\text { Competition }\end{array}$ \\
\hline
\end{tabular}

\begin{tabular}{|l|l|}
\hline & \\
\hline & \\
\hline & \\
\hline & \\
\hline & \\
\hline & \\
\hline & \\
\hline & \\
\hline
\end{tabular}




\section{Controlling Negative Self Statements (Step 3.2) \\ Training Plan}

Consider situations in the past (or anticipate events that may occur in the future) and determine some potential (or actual) negative self-statements. In each situation, consider what caused the negative self-talk and how you will react to it (recall the $3 \mathrm{R}^{\prime}$ s from step 3.2 ).

\begin{tabular}{|c|c|}
\hline $\begin{array}{c}\text { List Your Common Negative } \\
\text { Self-Statements During or } \\
\text { Before Competition: }\end{array}$ & $\begin{array}{r}\text { In The Future, What Should } \\
\text { Oo Should You Have Some } \\
\text { Of These Thoughts? }\end{array}$ \\
\hline
\end{tabular}

\begin{tabular}{|l|l|}
\hline & \\
\hline & \\
\hline & \\
\hline & \\
\hline & \\
\hline & \\
\hline & \\
\hline & \\
\hline
\end{tabular}




\section{Skill 4 Goal-setting}

(adapted from Orlick's "Psyching for Sport: Mental Training for Athletes")

Athletes can benefit greatly utilizing goal-setting in their training and at competitions. Establishing specific goals should help provide direction to your actions, provide a measure to determine whether you are attaining your goals, and encourage you to extend your limits. "Today's goals are tomorrow's realities." (Orlick)

To minimize disappointment and maximize feelings of self-confidence, athletes should be encouraged to set realistic self-improvement goals for each training session and also for each competition. Focus on factors within your control only. Ensure to set goals that are challenging to yourself. The goal should require dedication and practice before one can attain it.

\section{Step 4.1 Establishing Performance Outcome Goals (Long Term)}

In order to begin utilizing goal-setting, it is important to decide where you want to be within a specified time period (These goals should be stated to allow for measurement in order for your progress to be monitored). Don't sell yourself short in terms of possibilities. Dream a little.

Consider these three dimensions when determining your outcome goals:

1. Imagine what is potentially possible if all of your limits are stretched.

2. Set a realistic performance outcome goal based on your competitive history, current skill/ability level, and present motivation to improve.

3. Set a goal of overall self-acceptance, regardless of performance outcome. (Decide how you will accept not fulfilling your goal)

(Now complete the Goal Assessment Form found on page 14)

\section{Step 4.2 Establishing Performance Outcome Goals (Daily)}

Now that you have determined where you want to end up, it is imperative that you set daily goals for training and competition that will enable the long term goals to be realized. Day-to-day goals (personal goals) for training and for competitions should focus on the means by which you can draw out your own potential. Daily goals should be aimed at the improvement of personal control over your performance, yourself, and the obstacles that you face.

When determining your daily training goals, consider the following questions:

1. What am I going to do today (physical training/skill refinement goals)?

2. How am I going to approach what I'm going to do today (e.g., with intensity, concentration, positiveness)?

3. What am I going to do today to improve my mental strength (psychological training goals)? 
When determining your daily goals consider the following points:

- put the goals in writing

- goals should be flexible enough to allow for change (injury, etc.)

- all factors related to goal attainment should be taken into account (nutrition, current ability, are examples)

- goals should be stated to allow for evaluation of effort as well as performance

- frequently monitor goals and adjust when necessary

(Before and after each training session and/or competition, fill out the training/competition evaluation form found on page 15) 


\section{Goal Assessment Form \\ (adapted from Orlick)}

1. Dream Goal (long-term) - What is your long-term dream goal? What is potentially possible in the long term if you stretch all of your limits?

2. Dream Goal (this year) - What is your dream goal for this year? What is potentially possible if all of your limits are stretched this year?

3. Realistic Performance Goal (this year) - What do you feel is a realistic performance goal that you can achieve this year (based on your present skill level, your potential for improvement, and your current motivation)?

4. Self-Acceptance Goal - Can you make a commitment to accept yourself and to learn from the experience, regardless of whether you achieve your ultimate performance goal this year?

5. Can you set an on-site goal of best effort (giving everything you have that day) and be satisfied with achieving that single goal?

6. Psychological Goal (this year) - What do you feel is an important goal for you to focus on this year in terms of your psychological preparation or mental control? 


\section{Training/Competition Evaluation}

Name:

Date:

Complete questionnaire at each training session or competition. Provide information in as much detail as possible.

\section{Personal/performance goals:}

1. List overall goal(s) of training session/competition:

Achieved Goal(s)? List the contributing factors that helped or hindered the attainment of your goal(s). (e.g. nutrition, rest/sleep, energy level, etc.)

2. If one of your goals included a performance outcome goal, record the previous personal best time achieved for that goal:

3. Do you have any specific technique goals for this training session lany areas in need of attention)?

4. What are your mental training goals for this session/competition? le.g. emotion control, positive self-talk, imagery, etc.)

Achieved Goal(s)? List the contributing factors that helped or hindered the attainment of this goal. 


\section{Psychological Preparation: Using Mental Skills for Peak Performance}

Now that you've completed the mental skills training, you should be a more complete athlete. You now have control over your:

- level of arousal

- emotions and mood

- thoughts and self-statements

- overall ability to achieve your goals

Having completed the training journals and self-assessments, you have a better understanding of how the mental skills work. Keep in mind that mental skills are skills like any others and that you will have to continue to practice them and develop your ability to use them proficiently.

The next step is to formulate a structured plan in order to facilitate proper focus and feelings both before and during competition. Developing pre-competition and competition focus/refocus plans are an ideal way to integrate mental skills into a structured preparation strategy (refer to Orlick's Psyching For Sport: Mental Training for Athletes to further enhance your understanding of using mental skills for competition).

Considering the amount of training involved in attaining your personal goals, don't leave it to chance that you will be focused and have the appropriate feelings the day of the competition. Preparation is the key! 
(Appendix D)

Intervention Checklist

Signature of Observer:

Date:

\section{Session 1}

\section{Relaxation Training}

- Asked subject to read page 1

- Perform progressive muscle relaxation session (using cassette)

- Complete session 1 of progressive muscle relaxation journal

- Have subject read step 1.2

- Take subject through an example of centering while stretching

- Have subject read step 1.3

- provide an example using self-talk and imagery as well

- Remind subject to fill in journal on page 3

Imagery Training

- Have athlete read step 2.1

- Go through an imagery session with subject

- Complete session 1 of initial imagery journal

- Explain that subject must practice once a day for 3 days consecutively

- Have subject read step 2.2

- Stress "feel" and "creativity"

- Go through an example session

- Complete competition specific imagery training questionnaire

\section{Session 2}

\section{Check to see skill 1 and skill 2 exercises were completed}

\section{Self-talk}

- Have subject read page 8

- Discuss self-talk in relation to relaxation, imagery, pre-comp. plan

- Work through 2 examples of the self-talk exercise sheet (pg. 10)

- Have subject read page 9

- Explain refocusing (before/during competition)

- $\quad$ Go through 2 examples of step 3.2 training plan 


\section{Goal-Setting}

- Have subject read pages 12 and 13

- Go through goal assessment form and explain each question and refer to the appropriate information within the workbook

- Complete goal-setting sheet for the next session with the subject

- Get subject to read page 16 of manual

- Reinforce the pre-competition/competition plan idea

\section{General Comments:}

- Will contact subject daily to check on progress/compliance of exercises

- Will be using these skills at the next session

\section{Session 3 (day before first data collection session)}

\section{Check to see that skill 3 and skill 4 exercises were completed}

- Ask if there are any questions

- Copy questions down and answer them

- Check understanding with subjects for any of the previous questions that were asked by previous subjects 


\section{(Appendix E) \\ Social Validation Questionnaire For Participants}

i. How important is decreasing your $1600 \mathrm{~m}$ time in practice to you?

1

not important
2 3 somewhat important
5

very important

ii. How important is increasing the consistency of your $1600 \mathrm{~m}$ performance to you?

$\begin{array}{ccccc}1 & 2 & 3 & 4 & 5 \\ \text { not important } & & \text { somewhat important } & \text { very important }\end{array}$

iii. How useful was the mental skills package used in this study?

$\begin{array}{ccccc}1 & 2 & 3 & 4 & 5 \\ \text { not at all useful } & & \text { somewhat useful } & \text { very useful }\end{array}$

iv. Did you enjoy using the mental skills package used in this study?

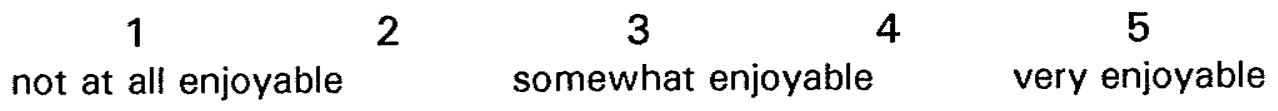

v. Are you satisfied with the results produced by utilizing the mental skills package?

1

not at all satisfied
2

$\stackrel{3}{\text { somewhat satisfied }}$
5 very satisfied

vi. General comments pertaining to your participation in the study or of the mental training program used (the workbook, the instructor, etc.) 


\section{(Appendix F) \\ Social Validation Questionnaire For Coaches}

i. How important is decreasing an athlete's $1600 \mathrm{~m}$ time in training?

1

not important
2
5

very important

ii. How important is increasing the consistency of an athlete's $1600 \mathrm{~m}$ performance in training?

$\begin{array}{lllll}1 & 2 & 3 & 4 & 5\end{array}$

not important somewhat important very important

iii. In your opinion, considering each athlete's graph one at a time, would you consider the decrease in time to complete the $1600 \mathrm{~m}$ run significant?

Subject 1 Y Yes __ No Comments:

Subject 2 Yes ___ No Comments:

Subject 3 Yes No Comments: 